\title{
Modeling the deep convection in the northwestern Mediterranean Sea using an eddy-permitting and an eddy-resolving model: Case study of winter 1986-1987
}

\author{
Marine Herrmann, ${ }^{1}$ Samuel Somot, ${ }^{2}$ Florence Sevault, ${ }^{2}$ Claude Estournel, ${ }^{1}$ \\ and Michel Déqué ${ }^{2}$ \\ Received 25 October 2006; revised 15 October 2007; accepted 6 December 2007; published 12 April 2008.
}

[1] In the northwestern Mediterranean Sea, winter 1986-1987 was particularly cold, inducing a strong open ocean convection event. In order to investigate the impact of numerical models spatial resolution on the convection representation and the effects of deep convection on the northwestern Mediterranean circulation, we perform two numerical three-dimensional simulations (eddy-permitting versus eddy-resolving). Models are forced at the surface by the ERA40 atmospheric fluxes, with a simple heat flux correction to better mimic the observed value. We examine the characteristics of the deep convection (mixed layer, water masses characteristics, convection zone, and mesoscale structures) and perform temporal analysis of this event in terms of kinetic energy, buoyancy equilibrium, and deep water (DW) evolution. The convection characteristics are similarly represented on a global scale by both models and are in good agreement with observations, except for the size of the convection region. However, the eddy-resolving model better reproduces the mesoscale structures, whose role in the DW formation, mixing, and transport is shown to be essential. The boundary circulation and the overturning are enhanced during the convection event. Sixty-six percent of the DW spreading is due to the bleeding effect into the Catalan sea during the convection event, whereas $33 \%$ is due to the mesoscale structures southwestward advection after the event. Sixty percent of the restratification with respect of the water column initial structure occurs before July 1987 and is due to light water advection. Afterward, restratification is due to the mixing and is not complete before next year convection.

Citation: Herrmann, M., S. Somot, F. Sevault, C. Estournel, and M. Déqué (2008), Modeling the deep convection in the northwestern Mediterranean Sea using an eddy-permitting and an eddy-resolving model: Case study of winter 1986-1987, J. Geophys. Res., 113, C04011, doi:10.1029/2006JC003991.

\section{Introduction}

[2] The Mediterranean Sea and more particularly the northwestern Mediterranean Sea (NWMS) is one of the few regions in the world where open ocean deep convection occurs (for a thorough review about open ocean convection, see Marshall and Schott [1999]). In this oligotrophic basin this process plays a major role in the functioning of biological pelagic ecosystems: phytoplanktonic spring blooms intensity is related to the amount of nutrients transported from the bottom to the surface euphotic zone during winter convection episodes. Atmospheric conditions, namely strong northerly winds and negative heat fluxes, combined with local anticlockwise oceanic circulation largely drive winter deep convection. Several observations campaigns have been realized in this region [MEDOC Group, 1970; Gascard, 1978; THETIS Group, 1994). They revealed that the NWMS

\footnotetext{
${ }^{1}$ Laboratoire d'Aérologie, Université Paul Sabatier, Toulouse, France.

${ }^{2}$ Centre National de Recherches Météorologiques, Toulouse, France.
}

Copyright 2008 by the American Geophysical Union. 0148-0227/08/2006JC003991 convection, centered around $\left(5^{\circ} \mathrm{E}, 42^{\circ} \mathrm{N}\right)$, has an important interannual variability and reaches the bottom $(2200 \mathrm{~m})$ during strong convection winters, like winter 1986-1987. This period is of great interest for convection studies since it was a very cold and windy winter with an intense convection episode that has been monitored during a dedicated campaign reported by Schott and Leaman [1991] and Leaman and Schott [1991].

[3] Mesoscale structures play an important role during deep convection. Baroclinic mesoscale instabilities have indeed been observed during deep convection events in the Mediterranean Sea [Gascard, 1978; Testor and Gascard, 2003, 2006] but also in other regions where deep convection occurs, like the Labrador Sea [Gascard and Clarke, 1983; Lilly et al., 2003]. The role of these structures in the sinking and spreading of the deep water (DW) formed during the convection event was shown by numerical studies [Madec et al., 1991b; Legg and Marshall, 1993; Send and Marshall, 1995; Jones and Marshall, 1997; Katsman et al., 2004] and observations analysis [Testor and Gascard, 2006]. Numerical studies [Madec et al., 1991b] and observations [Send et al., 1996] suggested that 
the newly formed DW could also be drained off the convection area by bleeding into the boundary current flow. Further evaluations of the respective contributions of these mechanisms in the DW spreading would be helpful for understanding the connection between deep convection and thermohaline circulation.

[4] Convection and DW formation three-dimensional numerical studies concerning the Mediterranean Sea have been realized by several investigators. $W u$ and Haines [1996, 1998] performed long-term simulations on the whole Mediterranean basin and underlined the importance of Levantine Intermediate Water (LIW) in the circulation and DW formation process in the Mediterranean. Wu et al. [2000], Stratford and Haines [2002], and Bozec et al. [2006] investigated the changes and variability of deep waters formation and thermohaline circulation in the eastern Mediterranean during the past decade. Castellari et al. [2000] and Artale et al. [2002] investigated the influence of atmospheric forcing on the Mediterranean thermohaline circulation and water mass formation processes. Castellari et al. [2000] and Somot et al. [2006] used long-term simulations to study DW formation interannual variability. Some investigators studied more specifically the eastern Mediterranean basin. Lascaratos and Nittis [1998] studied the formation of LIW and the influence of baroclinic eddies on the convection process. Bergamasco et al. [1999] and Mantziafou and Lascaratos [2004] explored the influence of forcings on the winter circulation and thermohaline structure of the northern Adriatic.

[5] Several numerical studies concerning deep convection in the western Mediterranean Sea have been carried out. Madec et al. [1991a, 1991b] used eddy-resolving simplified rectangular models to investigate the effect of thermohaline forcing variability on the DW formation in the NWMS as well as the role of baroclinic instabilities during the restratification. Madec et al. [1996] explored the effect of wind stress, thermohaline forcing, $\beta$ effect and topography on the large-scale preconditioning of DW formation. Those theoretical studies greatly advanced the knowledge of DW formation in the NWMS. Demirov and Pinardi [2007] investigated the role of eddies on the formation and spreading of water masses in the western Mediterranean Sea using an eddy-permitting model. More realistic studies with eddy-resolving models and comparisons of model results with observations would now be useful to understand and represent more precisely those processes. In particular, given the importance of mesoscale dynamics in these processes, it would be interesting to evaluate the impact of model resolution on numerical convection simulations in the NWMS.

[6] Winter 1986-1987 was studied using a onedimensional model [Mertens and Schott, 1998], and threedimensional studies were performed by Somot [2005] and Demirov and Pinardi [2007] with low-resolution eddypermitting models under realistic air-sea forcing. This period was not studied using an eddy-resolving threedimensional model. The objectives of this paper are to perform a three-dimensional high-resolution modeling of this real case under realistic forcing in order to investigate the impact of ocean model resolution on the simulation of deep convection in the NWMS, to study the effects of deep convection on the NWMS circulation, and to quantify the role of eddies in the DW spreading. We use two threedimensional primitive equations oceanographic models with different resolution. The eddy-permitting model is first used to perform a simulation on the entire Mediterranean basin. Second, the circulation in the NWMS is simulated with the eddy-resolving model embedded in the eddy-permitting model, as done by Mounier et al. [2005] to study the NWMS circulation during Winter 1999-2000 and by Echevin et al. [2003] to study the NWMS mesoscale circulation. Results of ECMWF 40-year reanalysis ERA40 [Simmons and Gibson, 2000] are used to prescribe atmospheric surface fluxes. Simulations results intercomparison and comparison with available observations allow us to evaluate the quality of the oceanic processes numerical representation for both models and to determine the advantages offered by the use of an eddy-resolving versus eddy-permitting model. We investigate in particular the impact of resolution on the mesoscale structures representation and the resulting effects on the mixed water column characteristics. The results of the eddy-resolving simulation are then used to study the impact of deep convection on the NWMS circulation and the role of eddies and boundary current in the DW spreading and the restratification.

[7] Winter 1986-1987 case study is presented in section 2. The two numerical models as well as the atmospheric forcing are described in section 3. Differences between both simulations are presented and discussed in section 4 . The effects of deep convection on the NWMS circulation are studied in section 5. Final conclusions and perspectives of this work are exposed in section 6 .

\section{A Case Study: Winter $\mathbf{1 9 8 6}-\mathbf{1 9 8 7}$}

[8] Several observation campaigns took place in the Gulf of Lions since MEDOC'69 [MEDOC Group, 1970]. Winter deep convection and the subsequent formation of the western Mediterranean Deep Water (DW) during the very cold and windy winter 1986-1987 were observed during a specific 6-week oceanographic campaign, MEDOC'87, reported by Schott and Leaman [1991] and Leaman and Schott [1991]. Observations obtained during a cruise with R/V Akademik Mstislav Keldysh between 4 and 8 March are reported by MEDAR/MEDATLAS Group [2002]. Mertens and Schott [1998] and Béthoux et al. [2002] provide a list of the deep/weak convection years respectively in the open sea and in the Gulf of Lions: in both studies, winter 1986-1987 is considered as a strong convection winter. Available observations, meteorological measurements at coastal stations and results from the PERIDOT model (the forecasting model used by Météo-France at this time) provide the following information. Three meteorological events (intense northern wind and depressions) associated with strong negative heat and buoyancy fluxes occurred during the observed period, i.e., between early December and late February (DJF). Daily mean heat flux was lower than $-1000 \mathrm{~W} \mathrm{~m}^{-2}$ during several days, and reached $-1500 \mathrm{~W} \mathrm{~m}^{-2}$ in mid-January [Mertens and Schott, 1998]. Between 17 and 26 February (MEDOC87 Leg IV) convection reached the bottom, i.e., $2200 \mathrm{~m}$, the convection zone defined by $S \geq 38.40$ psu formed approximately a triangle whose coordinates were $42^{\circ} \mathrm{N}-4^{\circ} \mathrm{E}$, $43^{\circ} \mathrm{N}-6^{\circ} \mathrm{E}, 41.5^{\circ} \mathrm{N}-5.5^{\circ} \mathrm{E}$, and the characteristics of the 


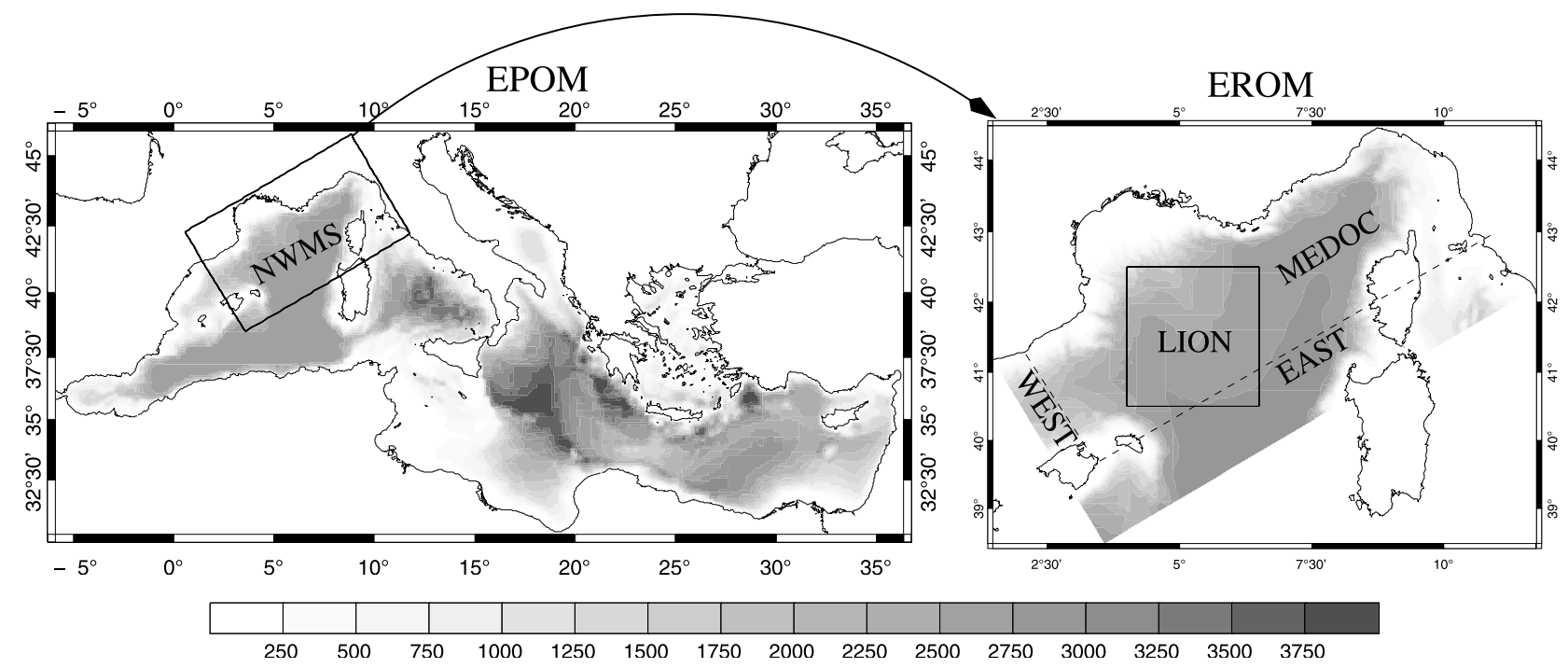

Figure 1. Bathymetry $(\mathrm{m})$ of the (left) EPOM and (right) EROM domains. The square in Figure 1 (right) represents the limit of the LION area, and the dashed lines represent the boundaries (East and West) of the MEDOC area.

DW formed were $12.76^{\circ} \mathrm{C}, 38.44 \mathrm{psu}, 29.11 \mathrm{~kg} \mathrm{~m}^{-3}$ [Leaman and Schott, 1991].

\section{Tools and Methods}

[9] The numerical studies are carried out using two ocean models: the Mediterranean basin eddy-permitting ocean model OPAMED and the coastal eddy-resolving ocean model SYMPHONIE. Both models are based on the hydrostatic assumption and the Boussinesq approximation and use a Arakawa $\mathrm{C}$ grid for the spatial discretization [Arakawa, 1972].

\subsection{Eddy-Permitting Oceanic Model: OPAMED}

[10] A Mediterranean Sea limited area version of the 3-D primitive equation numerical model Ocean Parallel [Madec et al., 1998] is used in this study. This model, called OPAMED, is described in detail by Somot et al. [2006]. It is based on the 8.1 version of OPA, very close to the one developed for the Mercator project [Drillet et al., 2005; Béranger et al., 2005]. The horizontal resolution is $1 / 8^{\circ} \times$ $1 / 8^{\circ} \cos (\Phi)$, where $\Phi$ is the latitude. This is equivalent to $10 \mathrm{~km}$ in the NWMS, approximately equal to the first Rossby deformation radius in this region: OPAMED is eddy-permitting. It has 43 vertical $Z$ levels with an irregular distribution. The OPAMED grid is tilted and stretched at the Gibraltar Strait to better follow the SW-NE axis of the strait, represented with two grid points. The modeled domain bathymetry is shown in Figure 1. The horizontal eddy diffusivity and viscosity coefficients are fixed to $-1.2 \times$ $10^{10} \mathrm{~m}^{4} \mathrm{~s}^{-1}$ for tracers (temperature, salinity) and dynamics (velocity) with the use of a biharmonic operator. A 1.5 turbulent closure scheme is used for the vertical eddy diffusivity [Blanke and Delecluse, 1993] and the vertical diffusion coefficient is enhanced to $1 \mathrm{~m}^{2} \mathrm{~s}^{-1}$ in case of unstable stratification.

[11] A buffer zone with a 3-D relaxation term for temperature and salinity is used to simulate the Atlantic ocean.
At the surface, the model is forced by radiative and air-sea fluxes: heat flux, water flux and wind stress. A sea surface temperature (SST) newtonian relaxation toward observed SST is applied as a first order coupling to allow the feedback of the model SST to the heat flux. A $40 \mathrm{~W} \mathrm{~m}^{-2} \mathrm{~K}^{-1}$ constant is applied for this relaxation [Barnier et al., 1995]. Atmospheric forcing is described in section 3.3. Explicit river runoff flux is added to make the water budget more realistic. Thirty-three different river mouths are included in OPAMED using the UNESCO RivDis database [Vörösmarty et al., 1996]. Climatological monthly values are used. The Black Sea is considered as a river for the Aegean Sea (for details, see Somot [2005]). The applied monthly values are computed from the work by Stanev et al. [2000]. For this study, initial conditions in August are taken from the last year of a 10-year spin-up for which 3-D relaxation has been applied for the Mediterranean Sea temperature and salinity toward the MedAtlas-II climatology [MEDAR/MEDATLAS Group, 2002]. This climatology, used as a reference in this study, also constitutes the initial conditions of the spin-up.

[12] In the eddy-permitting oceanic model (EPOM) simulation, the average water transport across the Gibraltar strait between September 1986 and September 1987 is $+1.4 \mathrm{~Sv}$. This is in the upper part of the observed values [Béthoux, 1979; Macdonald et al., 1994; Sannino et al., 2004]. The heat loss averaged over the Mediterranean Sea surface is equal to $-14.6 \mathrm{~W} \mathrm{~m}^{-2}$ whereas the heat net transport across the Gibraltar Strait is equivalent to a gain of $+7.2 \mathrm{~W} \mathrm{~m}^{-2}$. Two main reasons explain this heat deficit over the Mediterranean Sea. First, this particular year is really extreme in terms of heat loss [Mertens and Schott, 1998]. Second, the weak interannual variability of the Gibraltar heat transport (standard deviation less than $0.3 \mathrm{~W} \mathrm{~m}^{-2}$ over the 40 -year ERA40 period in EPOM [Somot, 2005]) does not allow a yearly balance between this heat transport and the surface heat loss that shows a high interannual variability (standard deviation equal to $3.4 \mathrm{~W} \mathrm{~m}^{-2}$ ). 


\subsection{Eddy-Resolving Oceanic Model: SYMPHONIE}

[13] The 3-D primitive equation coastal ocean model SYMPHONIE is described in detail by Marsaleix et al. [2006]. It has recently been used to study wind-induced circulation in the Gulf of Lions [Estournel et al., 2003; Auclair et al., 2003; Petrenko et al., 2005], circulation in the Bay of Fos [Ulses et al., 2005], dense water formation in the Gulf of Lions [Dufau-Julliand et al., 2004] and in the Gulf of Thermaikos [Estournel et al., 2005], and internal gravity waves [Pairaud and Auclair, 2005]. The horizontal grid is orthogonal, with a $3 \mathrm{~km}$ grid spacing 3.5 times smaller than the first Rossby deformation radius: the model is eddyresolving. A 40 vertical levels hybrid sigma-step coordinates system is used. The horizontal viscosity is $60 \mathrm{~m}^{2} \mathrm{~s}^{-1}$. Vertical eddy viscosities and diffusivities are calculated according to the Gaspar et al. [1990] second-order closure scheme, with a prognostic equation for the turbulent kinetic energy and an algebraic formulation of the mixing and dissipation lengths. In case of unstable stratification, a nonpenetrative convective adjustment algorithm, as described by Madec et al. [1991a] is used. Figure 1 shows the modeled domain.

[14] Boundary conditions have a double objective: the radiation of outgoing waves and the forcing of the inner solution by external fields provided by the basin model. As suggested by Blayo and Debreu [2005] and Marsaleix et al. [2006], this is achieved by applying our open boundary conditions schemes on the difference between the modeled and external variables rather than on the absolute variables. Lateral boundary conditions for eddy-resolving oceanic model (EROM) are provided at each time step by the time-interpolated monthly averaged results of the simulation performed with EPOM. EPOM outputs are made consistent with EROM characteristics using the variational inverse method VIFOP described by Auclair et al. [2000, 2006]. EPOM simulations also provide the initial conditions for EROM simulations. At the surface, the model is forced by air-sea fluxes: heat flux (the resultant of the sensible, latent, and radiative fluxes and the large-scale model EPOM SST relaxation term), water flux and wind stress. No SST relaxation is applied. The freshwater discharge of the Rhone river is introduced as a lateral boundary condition using the same climatological monthly values as EPOM.

\subsection{Atmospheric Forcing}

\subsubsection{ERA40 Data Set}

[15] Daily heat, water, and momentum fluxes coming from the ERA40 reanalysis [Simmons and Gibson, 2000] are used to force the ocean models from September 1986 to September 1987. Two weak points concerning the ERA40 data set have yet to be underlined in the framework of this study.

[16] First, the resolution, about $125 \mathrm{~km}$, could be considered as too low to induce ocean deep convection. Indeed, a spatial resolution of at least $50 \mathrm{~km}$ seems to be necessary in order to simulate the low-level regional winds directed by the orography (Mistral and Tramontane) as well as the associated strong latent and sensible fluxes [Somot, 2005]. This lowresolution results in an underestimation of the total winter period heat loss. A cumulated value of $-2.5 \times 10^{9} \mathrm{~J} \mathrm{~m}^{-2}$ over the convective area was reached for the DJF period as evaluated from coastline station data corrected for the landsea contrast [Mertens and Schott, 1998]. For the ERA40 data, the value computed in average over the LION area (defined in Figure 1) amounts to $-1.5 \times 10^{9} \mathrm{~J} \mathrm{~m}^{-2}$. This represents a $-130 \mathrm{~W} \mathrm{~m}^{-2}$ difference for each winter day. This difference is practically independent of the size of the averaging area. Indeed, a maximum winter heat flux difference of $4 \%$ is obtained between the LION area average and the average over the area northwest of $9.5^{\circ} \mathrm{E}$ and $40^{\circ} \mathrm{N}$. We applied homogeneously this $-130 \mathrm{~W} \mathrm{~m}^{-2}$ correction to the ERA40 heat flux. This correction is mainly justified by the lack of spatial resolution in ERA40. The advantage of our method is its simplicity and the fact that it does not modify the temporal variability of the heat flux. Madec et al. [1991a] indeed proved that the NWMS deep convection is very sensitive to the temporal variability of the forcing. Note that an OPAMED simulation performed with ERA40 forcing without this heat flux correction does not reproduce deep convection [Somot, 2005].

[17] The second problem is the water loss simulated by ERA40 over the Mediterranean Sea. This water flux is known to be too weak to obtain a realistic salinity over some decades [Mariotti et al., 2002; Josey, 2003]. However, we assume in this study that short simulations (1 year) are not very sensitive to this bias, as proved by Somot [2005]. Consequently, we do not apply sea surface salinity (SSS) relaxation in order to let its temporal and spatial highfrequency variability free.

\subsubsection{Evolution of the Atmospheric Fluxes During Winter 1986-1987}

[18] Temporal evolution of the daily atmospheric fluxes (wind stress $\tau$, corrected net heat flux $Q_{t o t}$, net water flux $E-P$ and buoyancy flux $B$ ) averaged over the LION zone between 1 December 1986 and 30 April 1987 (this period will be called DJFMA in the following) are presented in Figure 2. The following formula [Mertens and Schott, 1998] is used for $B$ :

$$
B=g\left(\frac{\alpha Q_{\mathrm{tot}}}{\rho_{0} C_{p}}-\beta \operatorname{SSS}(E-P)\right)
$$

where $g=9.81 \mathrm{~m} \mathrm{~s}^{-2}$ is the gravitational acceleration, $\rho_{0}=$ $1020 \mathrm{~kg} \mathrm{~m}^{-3}$ is the density reference, $C_{p}=4000 \mathrm{~J} \mathrm{~kg}^{-1} \mathrm{~K}^{-1}$ is the specific heat and $\alpha=2.10^{-4} \mathrm{~K}^{-1}$ and $\beta=7.6 \times 10^{-4}$ are the thermal and saline expansion coefficients. For the observed winter period (DJF), Figure $2 \mathrm{~b}$ shows three main meteorological events with strong negative heat flux, highlighted by gray bands: 22-25 December (event called E1 in the following), 11-16 January (E2) and 1620 February (E3). They are very well time-correlated with the three events mentioned by Mertens and Schott [1998], proving that ERA40 is able to reproduce an accurate chronology even at a subsynoptic scale. E1, E2 and E3 are characterized by an average heat loss of about $-450 \mathrm{~W} \mathrm{~m}^{-2}$ and a minimum daily value of about $-800 \mathrm{~W} \mathrm{~m}^{-2}$. These heat losses are very strong compared to the 1961-2000 ERA40 winterly mean value $\left(-150 \mathrm{~W} \mathrm{~m}^{-2}\right)$; however, they are underestimated compared to the ones given by Mertens and Schott [1998]. After correction of the land-sea effect, these authors indeed suggest event-averaged values of $-1000 \mathrm{~W} \mathrm{~m}^{-2}$ and daily peak of $-1500 \mathrm{~W} \mathrm{~m}^{-2}$. Similarly, Artale et al. [2002] obtain a maximum daily heat loss of $-1500 \mathrm{~W} \mathrm{~m}^{-2}$ for winter 1988. Because of its low spatial 

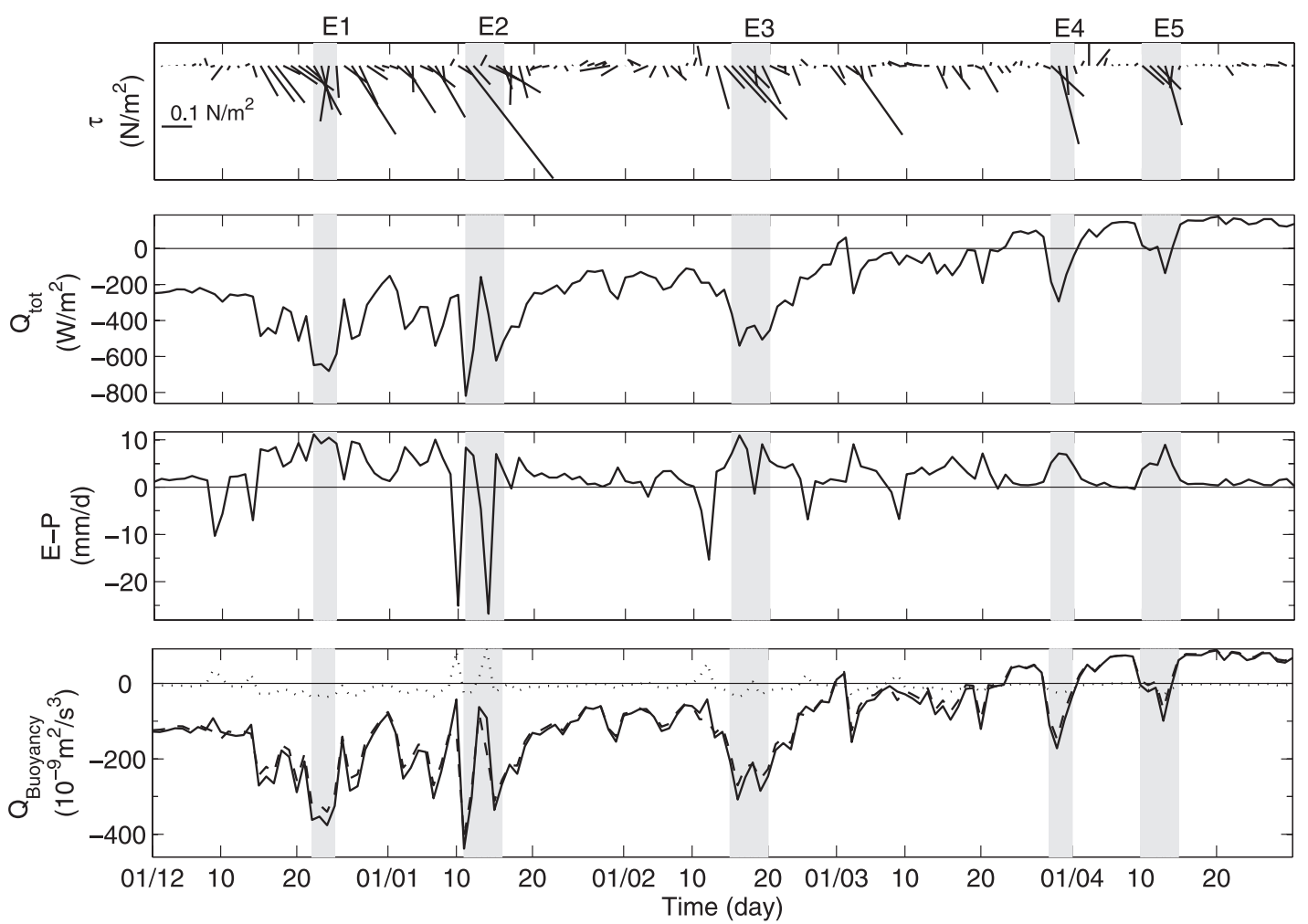

(d)

Figure 2. Evolution of the atmospheric fluxes averaged over the LION area between 1 December and 30 April 1987. From top to bottom, times series of the atmospheric forcing fluxes: wind stress $\left(\mathrm{N} \mathrm{m}^{-2}\right)$, surface atmospheric heat flux $\left(\mathrm{W} \mathrm{m}^{-2}\right)$, surface net water flux $\left(\mathrm{mm} \mathrm{d}^{-1}\right)$ and buoyancy flux $\left(10^{-9} \mathrm{~m}^{2} \mathrm{~s}^{-3}\right)$.

resolution, the ERA40 reanalysis is therefore not able to represent the local extremes. After the observed period, there are two additional events less intense than E1, E2 and E3 in ERA40 reanalysis: E4 at the end of March and E5, 10-15 April, also highlighted by gray bands.

[19] Figure 2 shows that the other air-sea fluxes (water, momentum, buoyancy) are time-correlated with the net heat flux. The five events with large heat losses always occur during Mistral-Tramontane periods with strong southward or southeastward winds (Figure $2 \mathrm{a}$ ). This wind forcing can act as a deep convection preconditioning by mixing the top of the ocean mixed layer through kinetic energy input. Moreover, in winter, this meteorological situation often occurs when a Mediterranean cyclone has been formed in the Gulf of Genova, leading to the advection of cold and dry continental air masses from the north and explaining the strong heat losses by sensible and latent heat fluxes. As the latent heat flux is often the driving term of the net heat flux, strong water losses are also correlated with these events. The departure from the winter average is, however, less important for the water flux than for the heat flux and some events are associated with rainy periods characterized by water gain for the sea (e.g., E2). As already noted by Artale et al. [2002], the water flux contribution to the buoyancy flux winter average and high-frequency variability is very weak compared with the heat flux contribution (Figure 2d), equal to $94 \%$ (83\% for Mertens and Schott [1998]). An integrated value of $1.27 \mathrm{~m}^{2} \mathrm{~s}^{-2}$ is obtained for the buoyancy loss over the DJF period, whereas Mertens and Schott [1998] obtain $1.5 \mathrm{~m}^{2} \mathrm{~s}^{-2}$. The discrepancy comes from the water flux part. The heat flux part indeed amounts to $1.20 \mathrm{~m}^{2} \mathrm{~s}^{-2}$, in very good agreement with Mertens and Schott [1998] $\left(1.25 \mathrm{~m}^{2} \mathrm{~s}^{-2}\right)$. For simulations longer than those used in this study, water flux correction should then be used [Somot, 2005].

[20] The applied heat flux correction therefore leads to a good agreement between the air-sea fluxes and winterly integrated observed data. Moreover this correction does not change the daily chronology and variability of the ERA40 fluxes. The individual meteorological events are not affected and are realistic, showing high temporal variability. Despite the lack of very strong spatial extremes, we have set up a realistic forcing data set which allows to study the winter 1986-1987 deep convection event.

\section{Impact of the Model Resolution on the Deep Convection Representation}

[21] This section deals with the modeling of the NWMS deep convection processes. We examine the water masses characteristics, the mixed layer depth evolution, the geographic characteristics of the convection zone and the mesoscale structures characteristics. For each process, we examine its representation by EPOM and EROM as well as the similarities and differences between these representations. Energetic, buoyancy and DW formed evolution analysis enable us to establish relationships between those characteristics and to explain the differences between EROM and EPOM simulations. We show that both models represent similarly the deep convection processes on a 

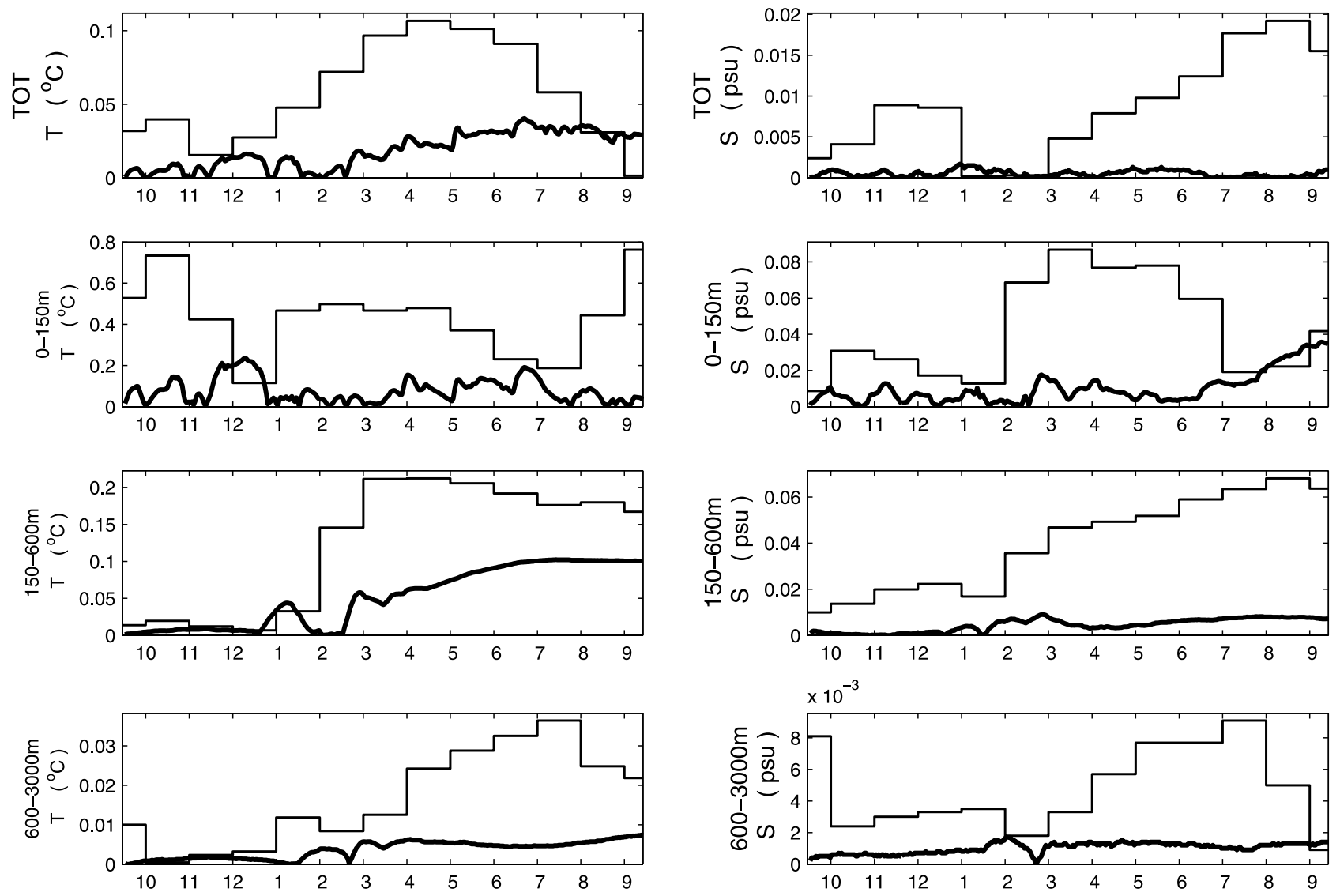

Figure 3. Evolution of the (left) temperature $\left({ }^{\circ} \mathrm{C}\right)$ and (right) salinity (psu) averaged over the EROM domain over the whole depth and over the $0-150 \mathrm{~m}, 150-600 \mathrm{~m}, 600 \mathrm{~m}$ bottom water layers between 15 September 1986 and 15 September 1987. Thick lines indicate daily absolute value of the difference between EROM and EPOM. Stairs indicate monthly absolute value of the difference between EPOM and the MedAtlas-II climatology [MEDAR/MEDATLAS Group, 2002].

global scale, and that the main difference is the mesoscale activity whose effects on the convection region and the evolution of the DW formed can then be examined.

\subsection{Evolution of the Water Masses Characteristics}

[22] We compare in Figure 3 the evolution of both models temperature and salinity averaged over the EROM domain and over different layers $(0-150 \mathrm{~m}, 150-600 \mathrm{~m}, 600 \mathrm{~m}$ bottom and $0 \mathrm{~m}$ bottom) during the simulation. The difference between EROM and EPOM is always well below the difference between MEDATLAS and EPOM, the global characteristics of the water masses are therefore similarly represented. Moreover, no conflict due to a difference between the water inside the zone and the boundary incoming water prescribed by EPOM can therefore appear in the EROM simulation.

[23] Temperature and salinity data are available for December 1986, March 1987 and July 1987 [MEDAR/ MEDATLAS Group, 2002; Leaman and Schott, 1991]. For each period, the observation area is indicated in Figure 4. Using these data and the results of EROM and EPOM obtained in the observed area (location also indicated in Figure 4) during the same periods, we compare temperature-salinity diagrams at different depths of the water column before, during and after the convection event (Figure 4).
[24] In December, both models are in agreement with the observations. However, the LIW characteristics, corresponding to water present at $500 \mathrm{~m}$ depth, are better represented by EROM.

[25] In March, a large group of points are between $38.40 \mathrm{psu}$ and $38.45 \mathrm{psu}$, and $12.70^{\circ} \mathrm{C}$ and $12.80^{\circ} \mathrm{C}$ in both models and in the observations. This corresponds to the vertically mixed water present in the convection region. Its characteristics are correctly represented by both models. The area above $29.1 \mathrm{~kg} \mathrm{~m}^{-3}$ where points of all depths are present corresponds to the DW formed during the convection event when the water column is fully mixed. We obtain the following characteristics for the DW formed: $12.74-12.76^{\circ} \mathrm{C}, 38.42-38.44 \mathrm{psu}, 29.10-29.12 \mathrm{~kg} \mathrm{~m}^{-3}$ for EPOM and $12.72-12.74^{\circ} \mathrm{C}, 38.42-38.43 \mathrm{psu}, 29.10-$ $29.11 \mathrm{~kg} \mathrm{~m}^{-3}$ for EROM. Both models therefore produce DW whose characteristics are very close to the observations $\left(12.76^{\circ} \mathrm{C}, 38.44 \mathrm{psu}, 29.11 \mathrm{~kg} \mathrm{~m}^{-3}\right.$ [Leaman and Schott, 1991]). The DW density is slightly higher in EPOM than in EROM. This could be explained by a stronger lateral advection of light water into the convection area in EROM due to mesoscale activity, as we will see in section 4.6. Moreover, this advection of light water can also explain the more important scatter in EROM than in EPOM. Second, for the observations, nonmixed water is present southeast and southwest of the observed area. This stratified water 

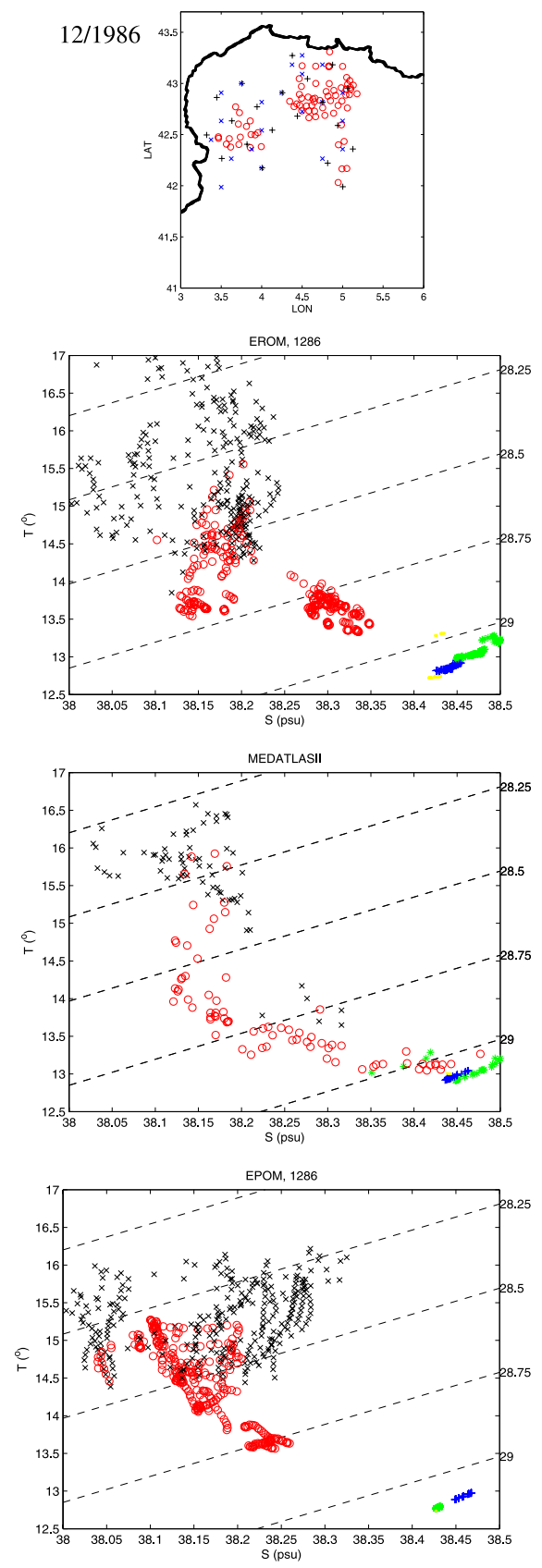
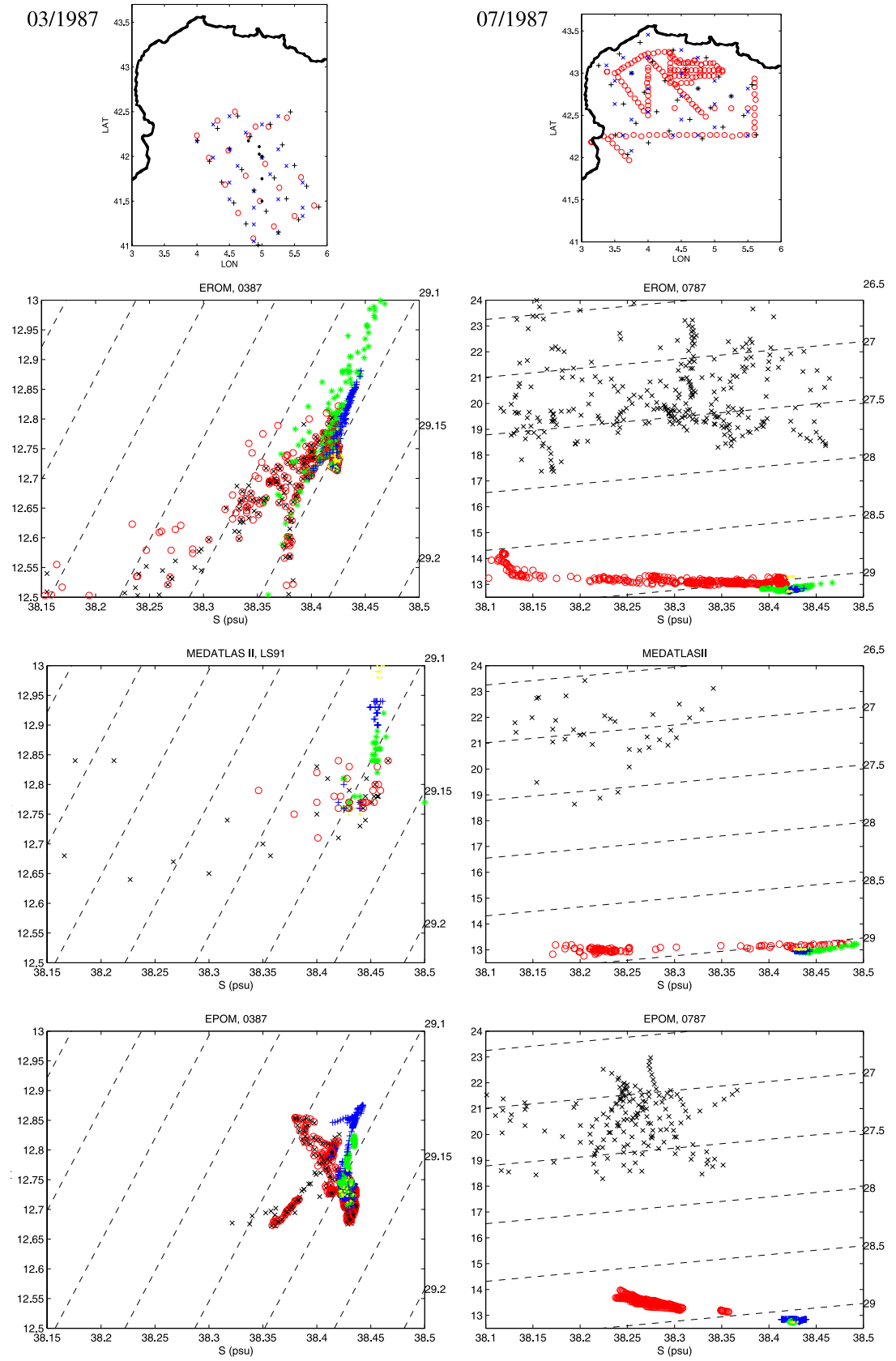
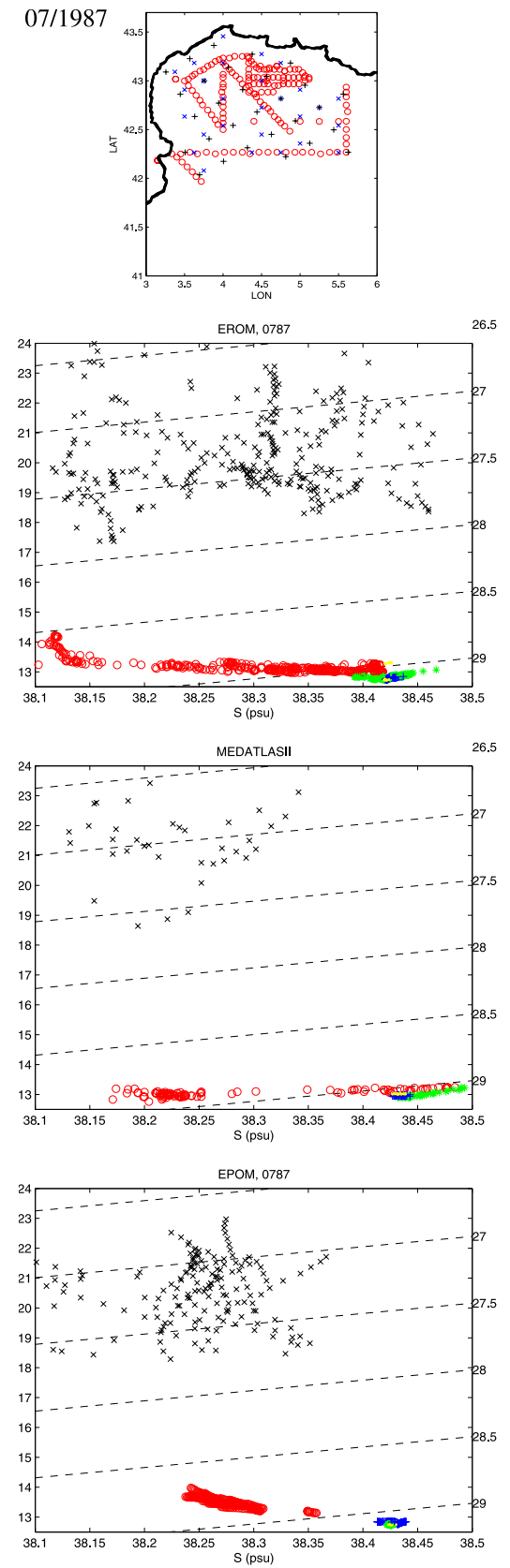

Figure 4. TS diagrams for the observations and the EROM and EPOM models (left) before (December 1986), (middle) during (March 1987) and (right) after (July 1987) the convection event. The location of the observations available in MEDATLAS is shown for each period on the maps of the top line (red circles), as well as the location of the observations reported by Leaman and Schott [1991] (black points), together with points of the EPOM (blue crosses) and EROM (black pluses) models used to produce the TS diagrams below. The second, third, and fourth lines show respectively the TS diagrams obtained for the EROM model, the observations, and the EPOM model using the points shown on the first line. Black crosses correspond to the $5 \mathrm{~m}$ depth level, red circles correspond to the $100 \mathrm{~m} \mathrm{level,} \mathrm{green} \mathrm{stars}$ correspond to the $500 \mathrm{~m}$ level, blue pluses correspond to the $1000 \mathrm{~m}$ level, and yellow points correspond to the $1500 \mathrm{~m}$ level.

corresponds to the low-salinity surface points and the hightemperature $\left(>12.85^{\circ} \mathrm{C}\right) 500 \mathrm{~m}$ points (corresponding to the LIW), $1000 \mathrm{~m}$ points $\left(>12.9^{\circ} \mathrm{C}\right)$ and $1500 \mathrm{~m}$ points $\left(>12.95^{\circ} \mathrm{C}\right)$. The characteristics of this water in the deep layers is the same as in December. In EROM, points of salinity lower than $38.3 \mathrm{psu}$ at the surface and at $100 \mathrm{~m}$ depth and of high temperature at $500 \mathrm{~m}\left(>12.9^{\circ} \mathrm{C}\right)$ and $1000 \mathrm{~m}\left(>12.8^{\circ} \mathrm{C}\right)$ correspond to the presence of stratified 
water in a small area southeast of the observed region. The surface temperature of this water is lower in EROM than in the observations and its salinity at $100 \mathrm{~m}$ depth is too low. This could be due to the atmospheric forcing, particularly to the homogeneous applied correction (section 3.3). This water is represented by EPOM, but is not present in the area used for comparison with the observations, and does therefore not appear on the TS diagram. Examining the salinity, temperature and current field in March for both models reveals that a small tongue of this cold and fresh water penetrates at the southeast corner of the comparison area thanks to a mesoscale structure in EROM. In EPOM this structure is not present and this water remains outside of the comparison area. The convection region in the observed area is therefore larger in EPOM than in EROM, and in EROM than in the observations. Third, a mass of water is present at the west of the observed area in EROM, corresponding to the cold $\left(<12.6^{\circ} \mathrm{C}\right)$ and salty $(>38.35 \mathrm{psu})$ surface, $100 \mathrm{~m}$ and $500 \mathrm{~m}$ points. This water is not observed in the data.

[26] In July, both models agree well with the observations. However, in EROM, there is a mass of surface water saltier than the observed water. This water corresponds to water present in the open sea. It also exists in EPOM, but it is not so close to the shelf. The intensity of the deep convection episode in the models, discussed in the following, can explain the presence of this water, not observed in the data. It can indeed result from dense water formed during the convection event that has not been completely evacuated in the models. Finally, the subsurface layer, including the LIW layer, is be better represented in EROM, as can be seen on the $100 \mathrm{~m}$ and $500 \mathrm{~m}$ point: restratification seems to be more complete in EROM. This could also be attributed to the mesoscale structures in EROM, whose role in the water masses advection after the convection event will be studied in section 5 .

[27] Finally, the characteristics of the water masses at different depths are globally in agreement with observations in both models during the whole simulation. However, the convection region seems to be larger in the models, particularly in EPOM, and mesoscale activity seems to be more intense in EROM than in EPOM.

\subsection{Mixed Layer Depth}

[28] The mixed layer depth (MLD) at each model grid point is defined using a threshold value of $4 \mathrm{~cm}^{2} \mathrm{~s}^{-1}$ for the vertical diffusion coefficient: the value of this coefficient is smaller, respectively larger than the threshold value in the mixed, respectively nonmixed regions. $\mathrm{MLD}_{\max }$, respectively $\mathrm{MLD}_{\text {mean }}$, on the LION zone (see Figure 1) is defined as the MLD spatial maximum, respectively average, over this zone. The evolution of $\mathrm{MLD}_{\max }$ and $\mathrm{MLD}_{\text {mean }}$ during DJFMA is presented in Figures 5a and 5b. This evolution is similar for both models and is consistent with the atmospheric forcing and the observations. Before E2 $\mathrm{MLD}_{\max }$ and $\mathrm{MLD}_{\text {mean }}$ are shallow and deepen slightly. The deepening begins at E2, in agreement with Leaman and Schott [1991], who noticed that a mid-January storm had set off deep convection prior to the start of the observation campaign. Between E2 and E3 the mixed layer deepens strongly. During E3 the deepening is the most abrupt $\left(\sim 80 \mathrm{~m} \mathrm{~d}^{-1}\right.$ for $\mathrm{MLD}_{\text {mean }}$ for both models versus $10 \mathrm{~m} \mathrm{~d}^{-1}$ for EROM and $22 \mathrm{~m} \mathrm{~d}^{-1}$ for EPOM between E2 and E3). For both models the mixed layer reaches the bottom at the end of E3, on 20 February (see Figure 5a, the difference between EROM and EPOM bottom values is due to the difference of bathymetry resolution). This corresponds to MEDOC87 leg IV observation period (17-25 February) during which observed convection reached the bottom [Leaman and Schott, 1991; Schott and Leaman, 1991]. Bottom convection lasts approximately until $25 \mathrm{March}$. At this time, restratification begins but is interrupted by E4 then, to a much lesser extent, by E5, after what restratification definitively goes on. Note that taking $3 \mathrm{~cm}^{2} \mathrm{~s}^{-1}$ like Artale et al. [2002] and $W u$ and Haines [1998] instead of 4 does not change the temporal evolution of the MLD and induces an average decrease of the maximum MLD values of $5 \%$ of the water depth.

[29] From the MLD study the different phases of the convection process, as defined by MEDOC Group [1970] and Madec [1990], can be identified: the preconditioning phase (until E2), the violent mixing phase (E3) and the sinking, mixing and spreading phase (after E4 and E5). We also identify the LIW mixing phase (between E2 and E3) during which the mixed layer crosses the LIW layer ( 500 m depth).

[30] The global temporal evolution of the MLD is similar for both models, and in good agreement with the observations; however, one observes some differences. Between E2 and E3 the deepening is stronger for EPOM $\left(52 \mathrm{~m} \mathrm{~d}^{-1}\right.$ for $\left.\mathrm{MLD}_{\max }\right)$ than for EROM $\left(40 \mathrm{~m} \mathrm{~d}^{-1}\right)$. The mixed layer reaches the LIW layer on 15 January for EPOM and $4 \mathrm{~d}$ later for EROM (Figure 5a). The deep water layer, defined by a density larger than $29.10 \mathrm{~kg} \mathrm{~m}^{-3}$ ( $\sim 1400 \mathrm{~m}$ depth), is reached on 1 February for EPOM and $13 \mathrm{~d}$ later for EROM. On the contrary during E3 $\mathrm{MLD}_{\max }$ deepening is more abrupt for EROM $\left(203 \mathrm{~m} \mathrm{~d}^{-1}\right)$ than for EPOM $\left(74 \mathrm{~m} \mathrm{~d}^{-1}\right)$. As a result both models mixed layer reaches the bottom nearly at the same time. Restratification occurs before E4 and E5, completely for EROM but not for EPOM. For EROM some processes, less important or not represented in EPOM, counteract the mixing of the stratified layer, slowing down the deepening of the mixed layer and accelerating its shallowing. Explanations for this difference will be proposed in the following.

\subsection{Geographic Characteristics of the Convection Zone}

[31] In section 4.1, the convection area seems to be larger in the models than in the observations, particularly for EPOM. Figure 6a shows the SSS on 20 February for both models. The triangle represents the limits of the convection zone observed during the MEDOC87 observation campaign, defined by a SSS larger than 38.40 psu [Leaman and Schott, 1991]. The global shape and position of the convection zone is similar for EROM and EPOM and corresponds approximately to the LION area. It is larger than the observed convection zone and extends too much southwestward. It is although relevant to point out that the track of the observation campaign did not cover the zone located southwest of the triangle. It is consequently difficult to conclude about the southwest extension of the observed convection zone. Figure $6 \mathrm{~b}$ shows the MLD in the MEDOC area (defined in Figure 1) on 20 February. The center of the deepest mixed layer area has the same position for both models $\left(4^{\circ} 30^{\prime} \mathrm{E}-41^{\circ} 30^{\prime} \mathrm{N}\right)$, outside of the observed con- 

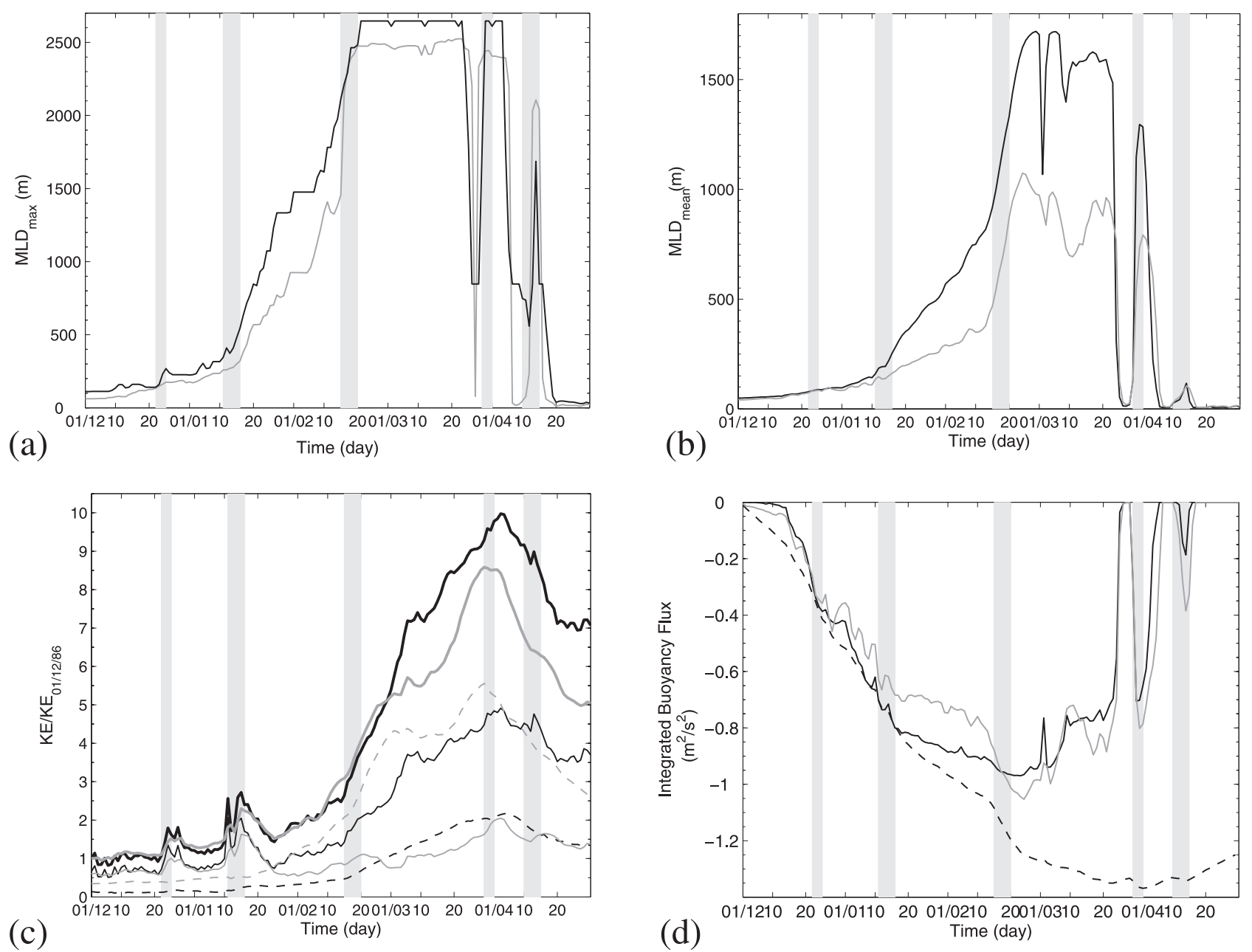

Figure 5. Evolution of the LION zone average characteristics between 1 December 1987 and 1 April 1987 (black lines, EPOM; gray lines, EROM): (a) maximum mixed layer depth MLD $_{\max }$ (m), (b) mean mixed layer depth $\mathrm{MLD}_{\text {mean }}(\mathrm{m})$, (c) kinetic energy. Thin full lines indicate large-scale kinetic energy LSKE. Dashed lines indicate small-scale kinetic energy SSKE. Thick full lines indicate total kinetic energy KE. (d) Integrated buoyancy flux $\left(\mathrm{m}^{2} \mathrm{~s}^{-2}\right)$. Full lines indicate columnar buoyancy as defined by (3). Dashed line indicates integrated surface buoyancy flux since 1 December 1986.

vection zone and $0.5^{\circ}$ southwest of the convection zone center cited by Leaman and Schott [1991], Madec et al. [1991b], and Mertens and Schott [1998]. As suggested by Madec [1990], this southwest displacement could be due to the low resolution of the atmospheric forcing or to the weakness of the cyclonic gyre that would induce a southwestward advection of the convection zone. This weakness can be explained by the wind forcing. This particular point is discussed at the end of the present paper.

[32] Figure 7 shows for both models the evolution during DJFMA of the size of the convection surface, defined as the area where $\rho>29.10 \mathrm{~kg} \mathrm{~m}^{-3}$ on the MEDOC area. There are two phases in this evolution. For EROM, it increases until E2. Between E2 and E3 it is $\sim 0.7 \times 10^{10} \mathrm{~m}^{2}$ then, after a strong increase during E3, it reaches its maximum $\left(\sim 2.9 \times 10^{10} \mathrm{~m}^{2}\right)$ until E5, then decreases. For EPOM, it increases until E3, the mean surface being $\sim 1.25 \times 10^{10} \mathrm{~m}^{2}$. The surface strongly increases during $\mathrm{E} 3$ and reaches its maximum $(\sim 5.3 \times$ $10^{10} \mathrm{~m}^{2}$ ) on 25 February. The convection surface is in average 1.5 times larger for EPOM than for EROM during the convection period.

[33] The average MLD over the LION area (Figure 5b) is proportional to the mixed volume over the LION area. The maximum mixed volume is smaller for EROM (43\% of the total LION volume) than for EPOM (71\%) (Figure 5b). $\mathrm{MLD}_{\text {max }}$ is quite similar for both models, particularly between E3 and E4 (Figure 5a). On the contrary during this period the convection surface and volume are approximately twice larger in EPOM than in EROM (Figures 5b and 7). The volume difference is therefore related to the horizontal extension difference rather than to the vertical extension difference. The volume where deep convection occurs has therefore approximately the same maximal depth in both models, but in EROM some processes limit its horizontal extension compared to EPOM.

\subsection{Mesoscale Structures}

[34] The main difference between both models is the mesoscale structures representation. These structures can 


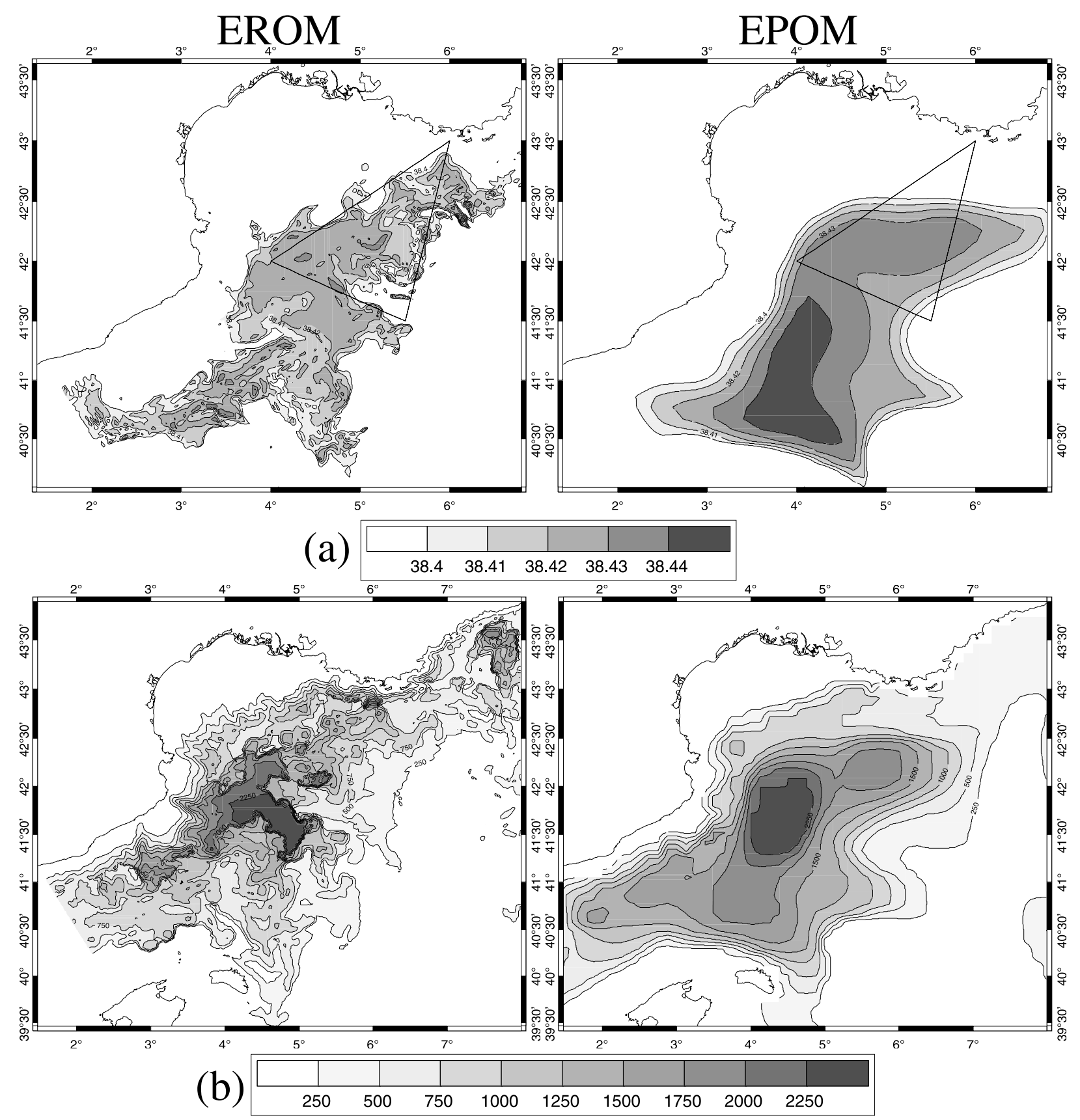

Figure 6. Convection zone on 20 February. (left) EROM. (right) EPOM. (a) Sea surface salinity (psu). Only isosurfaces corresponding to salinities higher than $38.40 \mathrm{psu}$ are represented. The triangle represents the observed convection zone, defined by a salinity larger than 38.40 psu [Leaman and Schott, 1991]. (b) Mixed layer depth (m).

be observed in Figures 6 and 8 where we show the surface density on 20 February and 20 March 1987, i.e., at the beginning of the violent mixing phase and just before the first restratification phase. For EPOM there are at both times two meanders of size $50-80 \mathrm{~km}$ southeast of the convection zone. This corresponds to the scale of the eddies observed by Demirov and Pinardi [2007] with a similar eddy-permitting model. For EROM smaller mesoscale structures are clearly visible at the periphery of the convection area at both times. In February the typical size of these structures varies between 15 and $35 \mathrm{~km}$. Small mesoscale structures are less present in March and the 15-35 km February structures have evolved into bigger structures whose typical size varies between 30 and $60 \mathrm{~km}$. These structures correspond to observed baroclinic instabilities [Gascard, 1978]. During the convection event, the stratification decreases, the Rossby radius of deformation therefore also decreases, and one could expect a decrease of the size of the eddies. However, the scale of the eddies formed in February increases, due to the functioning of the baroclinic instabilities. Madec et al. [1991b] indeed showed that the physical mechanism of the mesoscale structures 


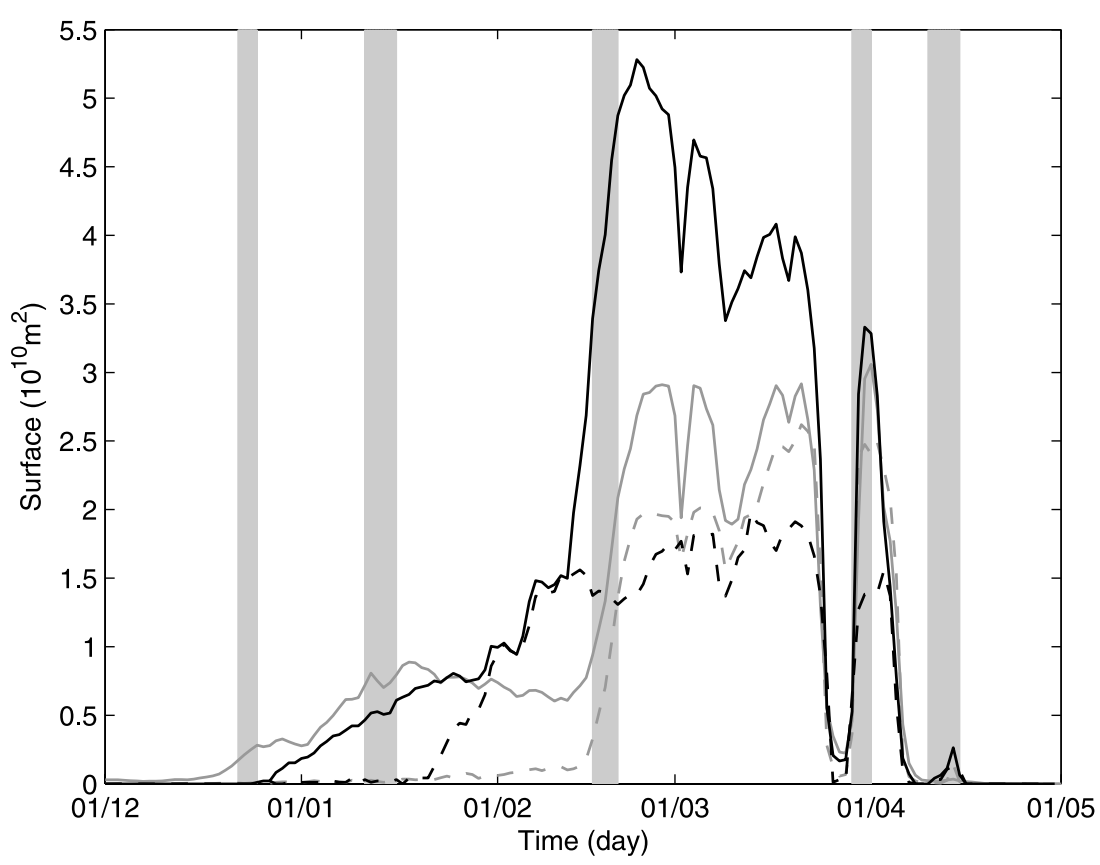

Figure 7. Convection surface $\left(10^{10} \mathrm{~m}^{2}\right)$ in the MEDOC area. Grey lines indicate EROM. Black lines indicate EPOM. Full line indicates surface where $\rho>29.10 \mathrm{~kg} \mathrm{~m}^{-3}$. Dashed line indicates surface where $\rho \in[29.095,29.105] \mathrm{kg} \mathrm{m}^{-3}$.

amplification is associated to the transfer of the potential energy of the density current to the eddy kinetic energy of the meanders and eddies. The size and location of these instabilities as well as their temporal evolution are more consistent with observations [Gascard, 1978; Sankey, 1973] and previous modeling studies made with eddy-resolving models Madec et al. [1991b, 1991a] in the NWMS and Lascaratos and Nittis [1998] in the Levantine Basin) for EROM than for EPOM.

[35] The mesoscale meanders that develop in EROM evolve into eddies, both cyclonic and anticyclonic, that are present in the area long after the convection episode. This is in agreement with observations reported by Testor and Gascard [2006]: after the deep convection event of winter 1994-1995, they observed both anticyclonic and cyclonic eddies of vertical scale larger than $1000 \mathrm{~m}$ and about $10-20 \mathrm{~km}$ in diameter, hence called submesoscale coherent vortices (SCVs), advecting newly formed DW away from the convection area. In the EROM simulation, the typical size of the eddies varies between 15 and $25 \mathrm{~km}$ on 1 March, and between 25 and $50 \mathrm{~km}$ on 15 April, after the convection event (to evaluate this size, we consider the diameter for which the velocity is maximum, as done by Testor and Gascard [2006]). We present the density and current fields at different depths of the water column on 15 April in Figure 9. We can identify at least five anticyclonic eddies (A1 to A5) and five cyclonic eddies (C1 to $\mathrm{C} 5)$ in the convection area but also out of this area (C5, A5). Characteristics of these eddies are presented in Table 1 . Cyclonic eddies are associated with local density maxima (i.e., an isopycnal doming) while anticyclonic eddies are associated with local density minima. A careful examination of the density and current fields during the previous days shows that the cyclonic structures transport dense water out of the convection area while the anticyclonic structures spread light water from the periphery to the center of the convection area. These eddies are all barotropic, they can be identified at each depth. Their orbital velocity is about $10-15 \mathrm{~cm} \mathrm{~s}^{-1}$ at the surface, it decreases with the depth and it is about $5 \mathrm{~cm} \mathrm{~s}^{-1}$ below $1000 \mathrm{~m}$ depth (Table 1). The corresponding rotation period varies between 7 and $11 \mathrm{~d}$. The vertical scale and orbital velocity of the eddies observed in the EROM simulation are in agreement with observations [Testor and Gascard, 2006, Table 2]. However, we were not able to identify anticyclonic eddies advecting dense water in the EROM simulation. Moreover, the eddies observed in this simulation at the end of the convection event are larger than the SCVs observed by Testor and Gascard [2006], and their rotation period is also consequently longer. This can be explained by the model resolution but maybe also by the longer duration of the convection event in 1986-1987 than in 1994-1995 (deep convection only occurred in early winter in 1994-1995). Indeed, the size of the eddies increases during the convection event in the EROM simulation and the size of the eddies observed on 1 March in our simulation is in better agreement with the observations than on 15 April. Finally, Testor and Gascard [2006] suggested that SCVs could be responsible for $40 \%$ of the spreading of newly formed DW away from the convection area. We will evaluate the role of these eddies in the spreading of the DW formed during the convection event in section 5 .

\subsection{Energetic Analysis}

[36] We perform an energetic analysis to study more precisely the evolution of the observed mesoscale structures. First, from the convection surface $S_{\text {conv }}$ (Figure 7), we compute a typical convection radius for each model $r_{\text {conv }}=$ $\sqrt{S_{\text {conv }} / \pi}$. We obtain two typical radii: $50 \mathrm{~km}$ between E2 and E3 then $100 \mathrm{~km}$ between E3 and E4 for EROM, and 


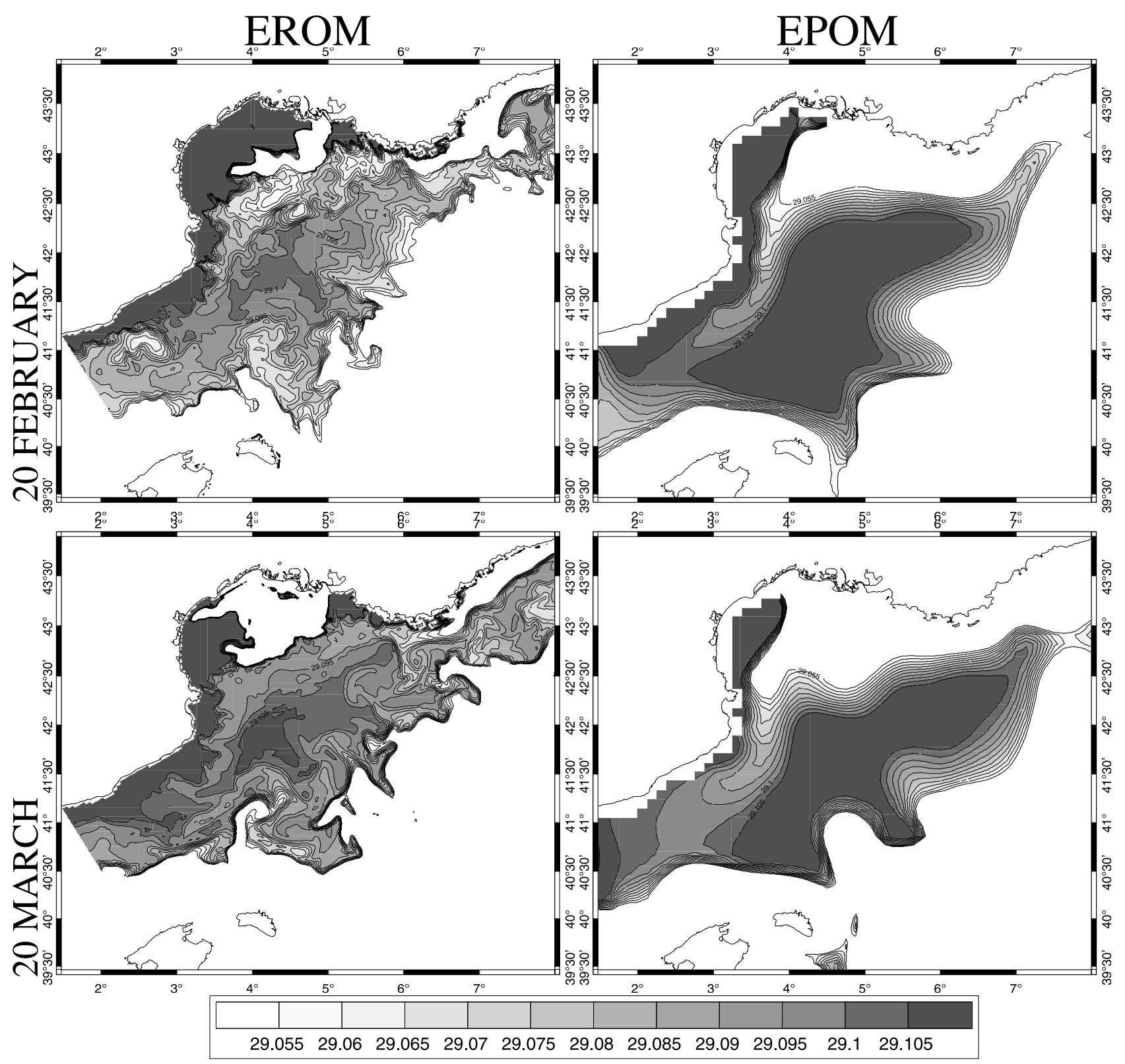

Figure 8. Sea surface density $\left(\mathrm{kg} \mathrm{m}^{-3}\right)$. (left) EROM. (right) EPOM. (top) 20 February. (bottom) 20 March. Only isosurfaces corresponding to densities higher than $29.05 \mathrm{~kg} \mathrm{~m}^{-3}$ are represented.

$65 \mathrm{~km}$ between E2 and E3 then $130 \mathrm{~km}$ on 25 February for EPOM. Visbeck et al. [1996] proposed a formula to compute the time required for eddies at the periphery of the convection zone to reach finite amplitude: $t_{\text {eddy }}=$ $12\left(r_{\text {conv }}^{2} / B\right)^{1 / 3}$ where $B$ is the buoyancy loss defined by (1). Lascaratos and Nittis [1998] used this formula to study baroclinic eddies in the Rhodes gyre. During the convection period we have $B \sim 1.9 \times 10^{-7} \mathrm{~m}^{2} \mathrm{~s}^{-3}$. We obtain $t_{1, \mathrm{EROM}} \approx 32 \mathrm{~d}$ and $t_{2, \mathrm{EROM}} \approx 51 \mathrm{~d}$ for EROM and $t_{1, \mathrm{EPOM}}$ $\approx 38 \mathrm{~d}$ and $t_{2, \text { EPOM }} \approx 62 \mathrm{~d}$ for EPOM.

[37] Circulation ocean models like EROM and EPOM are able to represent processes whose spatial scale is larger than 5-6 times the model resolution. EROM, respectively EPOM, should be able to represent processes of scale larger than $18 \mathrm{~km}$, respectively $60 \mathrm{~km}$. Sixty kilometers also correspond to the upper limit of the size of the mesoscale structures observed in the EROM simulation (section 4.4). Figure 5c presents for EROM and EPOM the evolution of the kinetic energy averaged over the LION area. We present the total kinetic energy (KE), the kinetic energy associated with processes of scale smaller than $60 \mathrm{~km}$ (small-scale kinetic energy, SSKE) and the kinetic energy associated with processes of scale larger than $60 \mathrm{~km}$ (large-scale kinetic energy, LSKE). To compute LSKE and SSKE, we compute the mean velocity over $60 \mathrm{~km}$ cells for both models and then compute the kinetic energy associated with this velocity (LSKE) and the kinetic energy associated with the total velocity minus this velocity (SSKE). To make things comparable we normalize the different kinetic energies by the $\mathrm{KE}$ on 1 December.

[38] The KE evolution is similar for both models until 25 January. The SSKE is small and stable. Peaks of KE that 

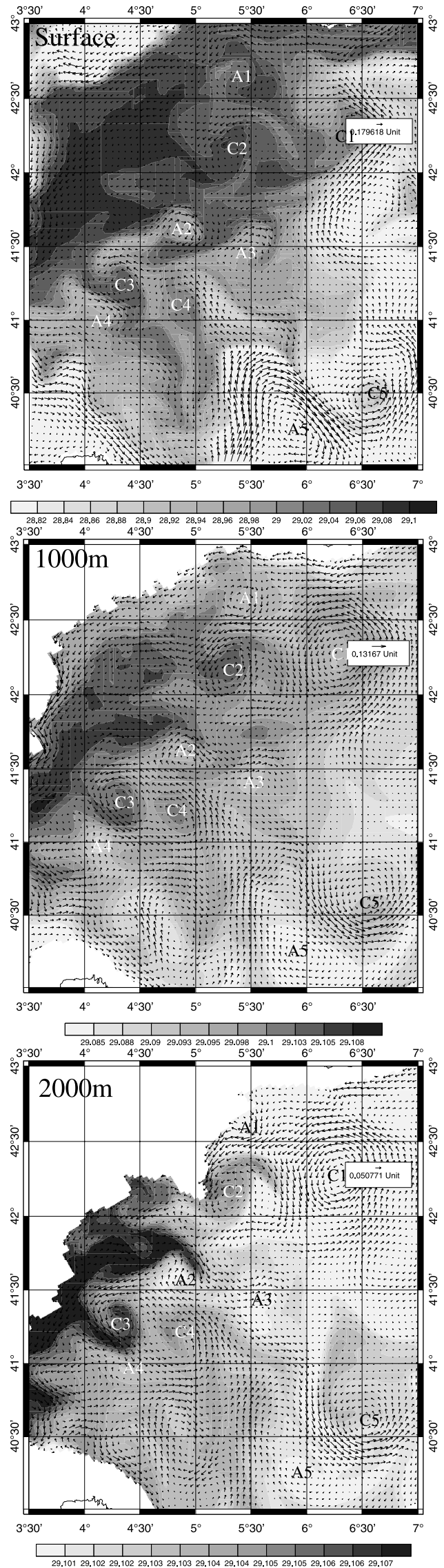

Figure 9. Density and current at 1, 1000, and $2000 \mathrm{~m}$ depth on 15 April 1987 in EROM.
Table 1. Characteristics of Eddies Observed on 15 April $1987^{\mathrm{a}}$

\begin{tabular}{cccccc}
\hline Eddy Identifier & $\mathrm{D}$ & $U_{\text {surf }}$ & $U_{1000}$ & $U_{\text {bot }}$ & $\mathrm{T}$ \\
\hline A1 & 25 & 10 & 5 & 3 & 9 \\
A2 & 30 & 15 & 4 & 4 & 7 \\
A3 & 30 & 10 & 2 & 1 & 11 \\
A4 & 32 & 15 & 5 & 7 & 8 \\
A5 & 50 & 15 & 5 & 3 & 11 \\
C1 & 45 & 15 & 5 & 5 & 11 \\
C2 & 30 & 13 & 3 & 3 & 8 \\
C3 & 35 & 15 & 7 & 7 & 8 \\
C4 & 25 & 13 & 5 & 3 & 7 \\
C5 & 40 & 15 & 5 & 5 & 10 \\
\hline
\end{tabular}

${ }^{\text {a Diameter }} D(\mathrm{~km})$, surface $U_{\text {surf }}, 1000 \mathrm{~m} U_{1000}$, and bottom $U_{\text {bot }}$ orbital velocity $\left(\mathrm{cm} \mathrm{s}^{-1}\right)$, rotation period $\mathrm{T}$ (days).

occur during E1 and E2 correspond to wind energy transfer to the sea surface and are associated with LSKE. Before E2 the kinetic energy is therefore associated with processes of scale larger than $60 \mathrm{~km}$, no strong mesoscale activity exists in the LION area. From 25 January to E3, $\mathrm{KE}$ increases similarly for both models. At E3 there is for both models an abrupt KE increase, until a local maximum on 25 February ( $30 \mathrm{~d}$ after the beginning of KE increase on 25 January) for EROM, and on 6 March ( $40 \mathrm{~d}$ after 25 January) for EPOM. For both models this period corresponds to the time $t_{1}$ computed above. However, the KE evolution is associated with LSKE increase for EPOM whereas it is associated with SSKE increase for EROM. This corresponds to the size of the structures observed in Figure 8 for 20 February described in section 4.4. For both models this local maximum occurs when restratification begins (Figure $5 \mathrm{~b}$ ).

[39] The KE reaches its absolute maximum on 29 March (63 d after 25 January) for EROM, and on 3 April (68 d after 25 January) for EPOM. It then decreases. This period corresponds to the time $t_{2}$ computed above and KE evolution during this period still corresponds to the size of the structures observed in Figure 8 for 20 March. Indeed, in EPOM, the LSKE is always at least twice larger than the SSKE, the convection episode is therefore mainly associated with the development of processes of scale larger than $60 \mathrm{~km}$. For EROM, between E3 and E4, the LSKE increases but always stays at least twice smaller than the SSKE and the KE maximum is still associated with SSKE.

[40] A spectral analysis of the kinetic energy over the LION area is performed for the EROM simulation to examine more precisely the evolution of the size of the most energetic processes. Results are presented on Figure 10 where the KE relative to the total KE on 01 December is plotted as a function of the wavelength. When the convection begins, in January, the maximum $\mathrm{KE}$ is obtained for wavelengths $\sim 15 \mathrm{~km}$, and this KE begins to increase. The $\mathrm{KE}$ increase is abrupt during the violent mixing phase that occurs in February, and still associated to wavelengths $\sim 15 \mathrm{~km}$. The wavelength of maximum energy then increases to $30 \mathrm{~km}$ at the end of March, i.e., the end of the convection event, and to $50 \mathrm{~km}$ at the end of April. This confirms the increase of the mesoscale structures size, already observed in section 4.4. This spectral analysis shows that the scale of the most energetic processes evolves from $15 \mathrm{~km}$ to $50 \mathrm{~km}$ during the winter for the EROM simulation. The KE evolution in EROM corresponds to the 

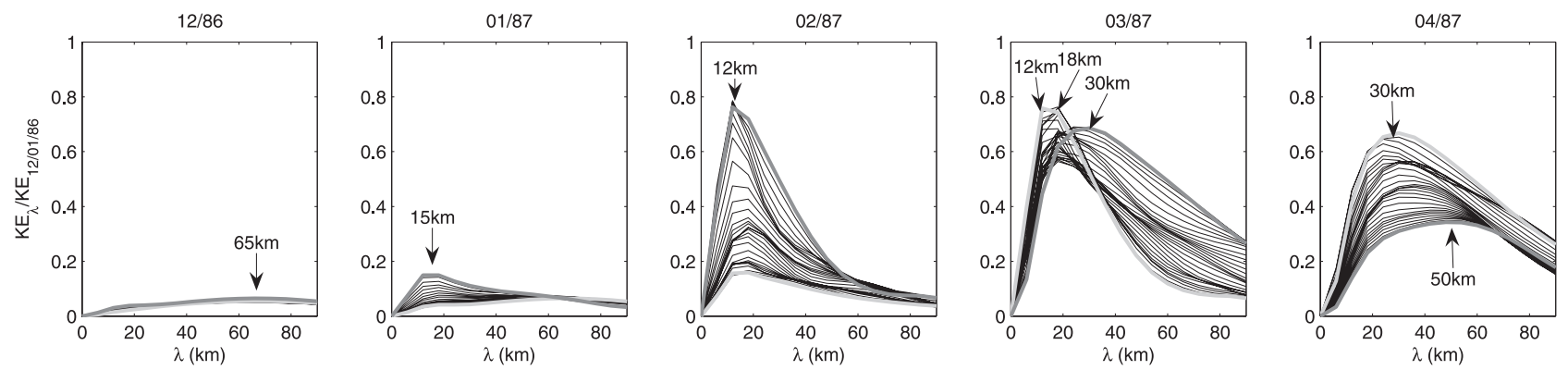

Figure 10. Spectra of the kinetic energy over the LION area for December 1986 and January to March 1987. The light gray, respectively dark gray curves, shows the spectra at the beginning, respectively end, of each month.

expansion of the mesoscale structures from $15-35 \mathrm{~km}$ to $30-60 \mathrm{~km}$, described in section 4.4, and is consistent with observations [Gascard, 1978] and previous modeling studies [Madec et al., 1991b, 1991a]. Moreover, there is approximately 1 month between the SSKE local maximum after E3 and the absolute maximum after E4. This is also in agreement with the cited studies.

[41] Using an eddy-permitting model with the same spatial resolution as EPOM, Demirov and Pinardi [2007] performed a spectral analysis of the kinetic energy in the Gulf of Lions. The KE associated to the $15-50 \mathrm{~km}$ range increases during the winter in their study; however, the maximum of $\mathrm{KE}$ is obtained for wavelengths larger than $50 \mathrm{~km}$. This result is in agreement with $\mathrm{KE}$ behavior observed in the EPOM simulation: the SSKE increases, but the maximum energy is associated to the LSKE. The most energetic processes correspond to scales larger than $60 \mathrm{~km}$ in those eddy-permitting models, whose resolution does not enable to represent very precisely the highenergetic mesoscale processes represented by EROM.

[42] This energetic analysis confirms that the convection episode is associated with the development of mesoscale structures whose spatial scale and evolution is more in agreement with observations and previous modeling studies in EROM than in EPOM. The LSKE evolution also shows that the large-scale circulation is activated during the convection episode.

\subsection{Buoyancy Analysis}

[43] The main difference between both models is their ability to represent mesoscale structures (sections 4.4 and 4.5). Theoretical studies [Legg and Marshall, 1993; Jones and Marshall, 1993; Marshall and Schott, 1999] suggested that these structures facilitate the transfer of buoyancy across the periphery of the convection zone by helping to the advection of lighter and stratified water into the convection area, hence slowing down the mixed layer deepening, reducing the convection volume and surface and helping to the restratification process. These consequences exactly corresponds to the differences between EROM and EPOM described in sections 4.1, 4.2, and 4.3. The effect of the mesoscale structures on the development of the convection area by lateral buoyancy flux advection is now studied by performing a buoyancy analysis as done by Artale et al. [2002]. The buoyancy flux required to mix an initially stratified water column down to the depth $h$ can be computed using the formula cited by Lascaratos and Nittis [1998]:

$$
\frac{\partial h}{\partial t}=\frac{B(t)}{N^{2}(h) h}
$$

where $\mathrm{N}\left(\mathrm{s}^{-1}\right)$ is the initial Brunt-Vaisala frequency and $B$ is given by (1). Separating the $h$-dependent and $t$-dependent terms and integrating (2), we obtain

$$
\int_{0}^{h_{\mathrm{lim}}} N^{2}(h) h d h=\int_{0}^{t_{\mathrm{lim}}} B(t) d t=\int_{0}^{t_{\mathrm{lim}}}\left(B_{\mathrm{surf}}(t)+B_{\mathrm{lat}}(t)\right) d t
$$

The left-hand side term of (3) represents the buoyancy loss that must be provided to the initially stratified water column to mix it down to the MLD $h_{\lim }$ at time $t_{\text {lim }}$, called columnar buoyancy. The right-hand side term represents the buoyancy flux integrated from the initial state to the time $t_{\text {lim. }}$. This buoyancy flux has two components: the surface flux $B_{\text {surf }}$ and the lateral flux $B_{\text {lat. }}$. Figure $5 \mathrm{~d}$ shows for each model the evolution of the average over LION of the columnar buoyancy and the integrated surface buoyancy flux. The difference between both curves corresponds to the lateral buoyancy flux into the LION area. The initial state is 1 December when $\mathrm{MLD}_{\text {mean }}$ is approximately zero (Figure 5b).

[44] Until E2 the columnar buoyancy is approximately equal to the integrated surface buoyancy flux for each model, there is no lateral buoyancy flux. This shows that the convection zone is well isolated by the cyclonic vortex. After E2 the columnar buoyancy becomes higher than the integrated surface buoyancy flux. This means that positive buoyancy is advected laterally into the LION area. Between $\mathrm{E} 2$ and $\mathrm{E} 3$ this advection is more important for EROM than for EPOM. This higher lateral advection is due to the mesoscale structures described in section 4.4: anticyclonic eddies advect light water into the convection area. During E3 the advection of lighter water is briefly interrupted in EROM, probably because of the annihilation of the mesoscale eddies by the strong wind event [Madec et al., 1991a]. $\mathrm{MLD}_{\text {mean }}$ increase is similar in both models $\left(\sim 80 \mathrm{~m} \mathrm{~d}^{-1}\right)$. However, the mixed layer has to cross shallower, therefore more stratified, water layers in EROM (Figure 5b). This explains the stronger columnar buoyancy decrease in EROM than in EPOM during this period. As soon as 

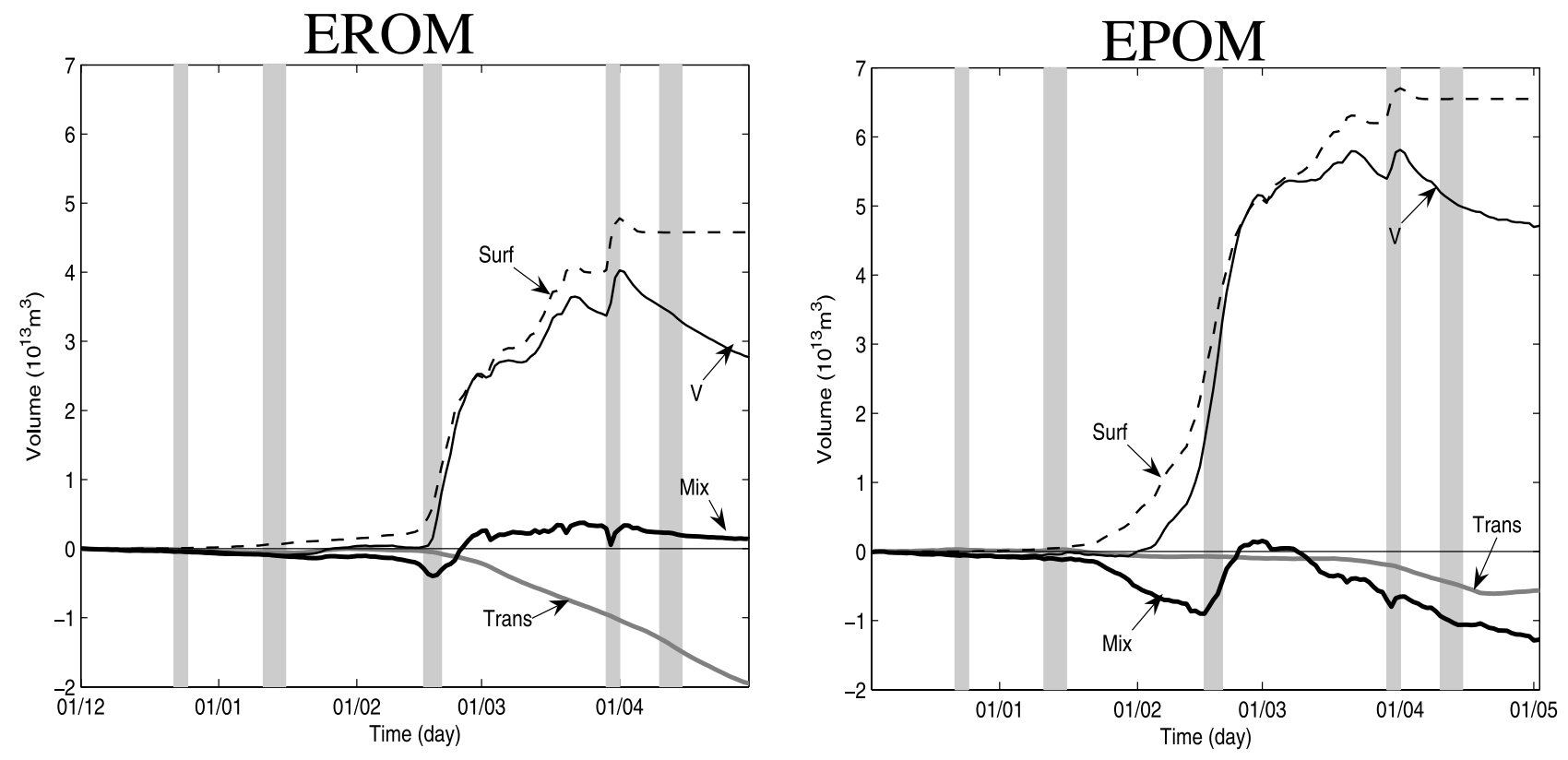

Figure 11. Evolution of the DW $\left(\rho>29.10 \mathrm{~kg} \mathrm{~m}^{-3}\right)$ between 1 December 1986 and 30 April 1987 in the MEDOC area for EROM and in the area north of $40^{\circ}$ and west of $9.5^{\circ}$ for EPOM. (left) EROM. (right) EPOM. Positive/negative values correspond to DW gain/loss. Gray line indicates integrated net transport across the MEDOC boundaries since 1 December. Thin black full line indicates total DW volume stored in the MEDOC area since 1 December. Black dashed line indicates volume of DW formed by the atmospheric fluxes since 1 December. Thick black full line indicates volume of DW produced by mixing since 1 December. Unit of $10^{13} \mathrm{~m}^{3}$.

restratification occurs, the difference between the columnar buoyancy and the integrated surface flux cannot be interpreted anymore.

[45] This buoyancy analysis confirms that the mesoscale structures described in section 4.4 are responsible for the lateral advection of positive buoyancy, i.e., of light water, into the convection area. This light water advection helps to maintain surface buoyancy and heat forcing, as we show in section 4.7. It is therefore essential to represent correctly the mesoscale structures in order to model correctly the timing of the convection episode and to stabilize the characteristics of the DW formed.

\subsection{Surface Formation, Storage, Mixing, and Export of DW}

[46] The analysis of the evolution of the DW formed during the convection episode enables us to investigate the impact of the resolution, and thus of the mesoscale structures, on this evolution during the convection episode. Figure 11 presents the evolution of the volume of DW $\left(\rho>29.10 \mathrm{~kg} \mathrm{~m}^{-3}\right)$ stored in the NWMS since 1 December $(V)$, the integrated net transport of DW in the NWMS since 1 December (Trans), the total volume of DW formed by the surface atmospheric fluxes since 1 December (Surf) and the total volume of DW consumed by mixing since 1 December (Mix). Because of model projections, the region used in the calculations is the MEDOC area (Figure 1) for EROM and the area north of $40^{\circ}$ and west of $9.5^{\circ}$ for EPOM. A negative transport corresponds to an export from the NWMS. The volume of DW produced at the surface by the atmospheric fluxes during the time $\Delta t$ is computed using
Walin's [1982] method as done by Tziperman [1986] and Speer and Tziperman [1992]: this volume corresponds to the volume of water that crosses the isopycnal $29.10 \mathrm{~kg} \mathrm{~m}^{-3}$ due to the surface fluxes. It can be evaluated using Speer and Tziperman's [1992] formula

$$
\Delta \text { Surf }=\frac{-\rho_{0}}{g \Delta \rho} \sum_{(x, y) / \rho(x, y) \in\left[29.10 \pm \frac{1}{2} \Delta \rho\right]} B \Delta x \Delta y \Delta t
$$

with $B$ given by (1), $\Delta x$ and $\Delta y$ the model resolution and $\Delta \rho=0.01 \mathrm{~kg} \mathrm{~m}^{-3}$. Integrating (4) between 1 December and $t$, we obtain Surf, the total volume of DW formed at the surface between 1 December and $t$. The volume consumed by mixing, Mix, is then computed using the conservation relationship

$$
V=\operatorname{Surf}+\operatorname{Mix}+\text { Trans }
$$

[47] For EROM the surface DW formation as well as the net transport, storage and mixing of DW are almost equal to zero until E2. Between E2 and E3, Surf increases very slightly, immediately consumed by mixing. Significant surface formation occurs between E3 and end of March, then between end of March and 5 April surface formation increases less abruptly. Most of this produced water is stored. After 5 April surface formation ceases and $V$ decreases, mainly due to net export.

[48] For EPOM surface formation, net export, storage and mixing of DW are equal to zero until E2. Significant surface formation begins at E2, i.e., 1 month sooner than in EROM. 
This water is first consumed by mixing then also stored from 5 February. From E3, Surf and $V$ increase until 25 February, then Surf increases less abruptly and most of the DW formed is exported and consumed by mixing. Surface formation definitively ceases at E4 and $V$ decreases, mainly due to mixing. For both models the DW volume storage approximately begins to increase when the mixed layer reaches the DW layer (Figure 5a). Right after E4, Surf and $V$ decrease slightly in both simulations, corresponding to the consumption of DW by the atmospheric fluxes.

[49] During the violent mixing phase, the quantity of water formed at the surface increases strongly for both models, due to the strong buoyancy loss. During this period, mixing produces $1.0 \times 10^{13} \mathrm{~m}^{3}$ of DW in EPOM and $0.6 \times$ $10^{13} \mathrm{~m}^{3}$ in EROM. In Figure 7 the difference between the full line and the dashed line represents the quantity of water whose density is higher than $29.05 \mathrm{~kg} \mathrm{~m}^{-3}$. Most of the density of the convection surface is greater than $29.105 \mathrm{~kg}$ $\mathrm{m}^{-3}$ after E3 for EPOM. DW can be formed by mixing of this very dense water with water lighter than $29.10 \mathrm{~kg} \mathrm{~m}^{-3}$. For EROM, for which the DW density is mainly in the $[29.095,29.105] \mathrm{kg} \mathrm{m}^{-3}$ range (Figure 7 ), DW is also formed by mixing with very dense water, but to a lesser extent. In EROM, the DW formed at the surface is indeed constantly mixed with less dense water by the baroclinic instabilities in EROM, which advect lighter water into the convection area. Consequently, the surface water density increases less for EROM than for EPOM and stays closer to $29.10 \mathrm{~kg} \mathrm{~m}^{-3}$. The baroclinic instabilities therefore stabilize the density of the DW formed.

[50] After this strong increase and until E4, $2.3 \times 10^{13} \mathrm{~m}^{3}$ of water is formed at the surface in EROM and $1.6 \times 10^{13} \mathrm{~m}^{3}$ is formed in EPOM. Most of the convection surface density is indeed greater than $29.105 \mathrm{~kg} \mathrm{~m}^{-3}$ for EPOM and not for EROM (Figure 7). A larger surface is therefore taken into account in (4). For EROM, surface formation is consequently constantly maintained by this mixing of very dense water with lighter water that stabilizes the density of the DW formed, explaining the higher volume of water formed at the surface during this phase.

[51] For EROM, the main terms in (5) are Surf and Mix between E2 and E3, Surf and $V$ between E3 and E5, and then $V$ and Trans. For EPOM, they are Surf, $V$, and Mix between $\mathrm{E} 2$ and $\mathrm{E} 3$, Surf and $V$ between $\mathrm{E} 3$ and $\mathrm{E} 5$, and then $V$, Mix, and Trans. On 30 April, for EROM, $4.6 \times 10^{13} \mathrm{~m}^{3}(97 \%)$ of water have been formed at the surface and $0.1 \times 10^{13} \mathrm{~m}^{3}$ (3\%) by mixing, of whom $2.8 \times 10^{13} \mathrm{~m}^{3}(59 \%)$ have been stored, $1.9 \times 10^{13} \mathrm{~m}^{3}(41 \%)$ have been exported. For EPOM, $6.6 \times 10^{13} \mathrm{~m}^{3}$ of DW have been formed at the surface of whom $4.8 \times 10^{13} \mathrm{~m}^{3}(72 \%)$ have been stored, $0.6 \times 10^{13} \mathrm{~m}^{3}(9 \%)$ have been exported and $1.2 \times 10^{13} \mathrm{~m}^{3}$ (19\%) have been mixed with less dense water. At each stage of the convection episode the transport is much more important in EROM than in EPOM, the proportion of exported water being twice larger in EROM than in EPOM. Mesoscale structures advect dense water out of the convection area (section 4.4), explaining this much higher export in EROM. This particular point will be studied more precisely in section 5.2 .

[52] This DW volume evolution analysis therefore underlines the essential role of the baroclinic instabilities in the DW surface formation, mixing and transport during the convection episode, and in the stabilization of the characteristics of the DW formed.

[53] The DW formation rate takes at once convection time, surface and depth into account. It can first be computed using Lascaratos and Nittis's [1998] method, also used by Castellari et al. [2000], i.e., dividing the maximum DW volume $V$ stored during the convection episode by the number of seconds in 1 year. The corresponding DW formation rate for EROM, respectively EPOM, over the NWMS area is $1.3 \mathrm{~Sv}$, respectively $1.8 \mathrm{~Sv}$, in agreement with Castellari et al. [2000] mean value for the NWMS $(1.6 \mathrm{~Sv})$. The higher formation rate for EPOM than for EROM is related to the larger three-dimensional EPOM convection zone and to the fact that DW formation begins earlier in EPOM. However, this method does not take export into account. Using Speer and Tziperman's [1992] method, i.e., using the volume of water formed at the surface Surf, rather than $V$, we obtain $1.5 \mathrm{~Sv}$, respectively 2.1 Sv, for EROM, respectively EPOM. With this method, Tziperman and Speer [1994] obtain a mean value of $1 \mathrm{~Sv}$ in the NWMS. However, winter 1986-1987 is a strong convection winter, our larger formation rates are therefore consistent with Tziperman and Speer [1992] rate. The higher formation rate for EPOM than for EROM with this method is related to the higher surface formation in EPOM. This method gives a higher formation rate than Lascaratos and Nittis's [1998] method since it does not take mixing and export into account. A more meaning method could be to take export and mixing into account by using $V+$ Trans, since it is actually the total remaining volume of water of density higher than $29.10 \mathrm{~kg} \mathrm{~m}^{-3}$. In this case, we obtain $1.5 \mathrm{~Sv}$, respectively $1.7 \mathrm{~Sv}$, for EROM, respectively EPOM. This rate is larger in EPOM, due to the larger storage.

[54] Between 30 April and 1 September 1987, in EROM, $1.3 \times 10^{13} \mathrm{~m}^{3}$ of DW have been consumed, $87 \%$ by advection and $13 \%$ by mixing, and $1.4 \times 10^{13} \mathrm{~m}^{3}$ are stored on 1 September. For EPOM, $0.9 \times 10^{13} \mathrm{~m}^{3}$ of DW have been consumed, $36 \%$ by advection and $64 \%$ by mixing, and $3.8 \times 10^{13} \mathrm{~m}^{3}$ are stored, approximately three times as large as in EROM. Mesoscale structures therefore also play an important role in the DW mixing and export after the convection episode. As a result, EPOM overestimates the memory effect of the DW in the LION area. This will probably influence the next winter stratification and consequently convection representation. It would be interesting to model the whole western Mediterranean with EROM to see the difference between the DW evolution in the whole area in both models over a longer period. Testor and Gascard [2006] and Demirov and Pinardi [2007] indeed suggest that eddies could transport this water during the months from the NWMS to the Algerian basin. Moreover, several authors demonstrated the importance of the intermediate water transport in the variability of the amount of DW formed in the NWMS [Wu and Haines, 1998; Artale et al., 2002] but also in the global thermohaline circulation [Calmanti et al., 2006; Straneo, 2004]. Béranger et al. [2004] and Millot and Taupier-Letage [2005] showed that mesoscale eddy shedding at the exit of the Sicily Strait and in the Algerian Basin was partly responsible for the transport of LIW in the western Mediterranean. This transport of LIW by eddies, not represented in EPOM, would certainly 
be better represented in a basin version of the EROM model.

\section{Effect of Deep Convection on the NWMS Circulation}

[55] It was shown in section 4 that the mesoscale structures constitute the main difference between EPOM and EROM representations of the deep convection. These structures have an upper scale of $60 \mathrm{~km}$ in EROM and play an important role in the lateral advection of positive buoyancy and in the DW formation and advection, in the timing of the convection, and in the stabilization of the characteristics of the DW formed. These structures being represented in EROM and not in EPOM, we now use results of the EROM simulation to assess the effects of deep convection on the NMWS circulation. We first focus on the effect of deep convection on the boundary circulation and overturning. We then evaluate the respective contributions of mesoscale structures and boundary current in the fate of newly formed DW during and after the convection episode. We finally study their role in the restratification by examining the destruction and rebuilding of the light water surface layer.

\subsection{Effect of Deep Convection on the Boundary Circulation and the Overturning}

[56] In this section the effect of deep convection on the boundary circulation and the overturning in the NWMS is investigated by examining the results of the EROM simulation. An analytical study by Crépon et al. [1989] and a quasi-geostrophic study by Barnier et al. [1989] showed that deep convection activates the boundary circulation in this area.

\subsubsection{Activation of the Boundary and Mesoscale Circulation}

[57] A detailed description of the circulation in the western Mediterranean Sea was proposed by Millot [1999]. The main current in this area is the Northern Current that flows in the upper part of the water column between 0 and $700 \mathrm{~m}$. The west and east Corsica branches of Modified Atlantic Water coming from the Sicilian strait join together in the Ligurian Sea and flow southward along the French Coast across the Gulf of Lions shelf. A branch continues along the Spanish Coast whereas the other branch bends eastward and forms the cyclonic circulation. These main characteristics of the NWMS circulation are correctly reproduced in the EROM simulation. The cyclonic boundary circulation that characterizes the boundary current in the area corresponds to negative values of the stream function $\phi$. We plot in Figure 12a the minimum of $\phi$, that represents the intensity of the cyclonic circulation. Before the convection event, $\phi$ is greater than $-2 \mathrm{~Sv}$. There are then two different timescales in the decreasing of the stream function minimum. First, after each meteorological event, $\phi$ reaches a local minimum during 1 or $2 \mathrm{~d}$. This high-frequency signal corresponds to the activation of the cyclonic circulation by the wind. Second, there is a global decrease of $\phi$ between the beginning of February and the last meteorological event, i.e., during the whole convection event. At the end of the convection event $\phi$ is smaller than $-8 \mathrm{~Sv}$. This decrease on a larger time scale, in agreement with LSKE increase during the convection event (section 4.5), corresponds to the enhancement of the cyclonic boundary circulation by deep convection. After the convection event, this activation of the circulation ceases and $\phi$ progressively increases, reaching $-3 \mathrm{~Sv}$ on 15 September 1987. $\phi$ is still smaller than before the convection event: the memory effect of this activation lasts several months.

[58] Mesoscale activity of the boundary current is also enhanced during the deep convection episode. As reported by Millot [1999], intense winter mesoscale activity of the Northern Current was observed by several investigators. This mesoscale activity is reproduced in our simulation and is synchronous with the convection event. The mesoscale activity of the Northern Current is pronounced in February, with meanders whose characteristics agrees with the observations reported by Millot [1999]: the size is a few tens of kilometers and the speed is around $6 \mathrm{~km} \mathrm{~d}^{-1}$. We observe this activity from mid-January until end of April. Before January and after April, no mesoscale activity can be observed.

\subsubsection{The Overturning Activation}

[59] The deep convection also activates the vertical NWMS circulation, as can be observed by examining the water flux at the boundary of the MEDOC area. Figure $12 \mathrm{~b}$ shows the vertical structure of the monthly net water flux at the MEDOC boundaries between December 1986 and August 1987. The net incoming flux in the $0-500 \mathrm{~m}$ layer is minimum in December and January, reaches a maximum between February and March and then decreases. Meanwhile, the flux in the lower layer becomes more and more negative, with a maximum net export in March and April in the 700-2000 m layer. From April the net export decreases, with a maximum near $1700 \mathrm{~m}$ depth. The flux at the MEDOC boundary can therefore be vertically divided in two main layers: the $0-500 \mathrm{~m}$ layer, with a net incoming flux that increases during the convection event, and the $500 \mathrm{~m}$ bottom layer, with a net outgoing flux that also increases. The daily net fluxes across the MEDOC boundary in the $0-500 \mathrm{~m}$ layer and the $500 \mathrm{~m}$ bottom layer is presented in Figure 12a. The net incoming flux in the $0-500 \mathrm{~m}$ layer and outgoing flux in the $500 \mathrm{~m}$ bottom layer increase during the three first meteorological events and then decrease gradually until the end of the simulation while the DW is progressively evacuated from the area. At the end of the simulation, these fluxes are still larger than before the convection event: the memory effect of this activation lasts many months. This increase of the surface net water import and the deeper layer net water export shows the activation of the overturning during the deep convection event in the NWMS.

[60] In conclusion, the boundary circulation is activated both vertically and horizontally during deep convection, in agreement with previous theoretical studies. Note that this enhancement is also observed in EPOM [Somot, 2005]. The enhancement of the mesoscale activity of the boundary circulation is also very well correlated with the deep convection episode.

\subsection{DW Spreading During and After Deep Convection: Role of the Boundary Current and the Mesoscale Structures}

[61] The knowledge concerning the spreading of DW during and after deep convection events still need to be 
(a)

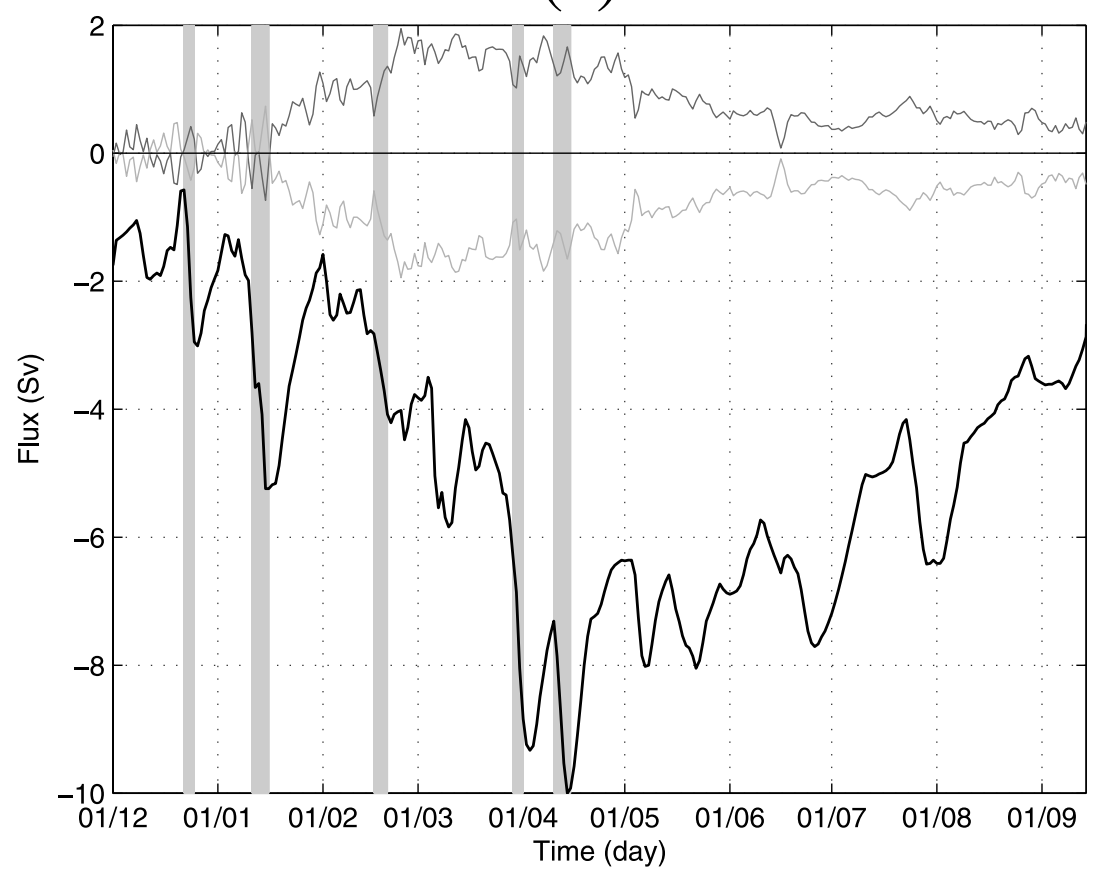

(b)

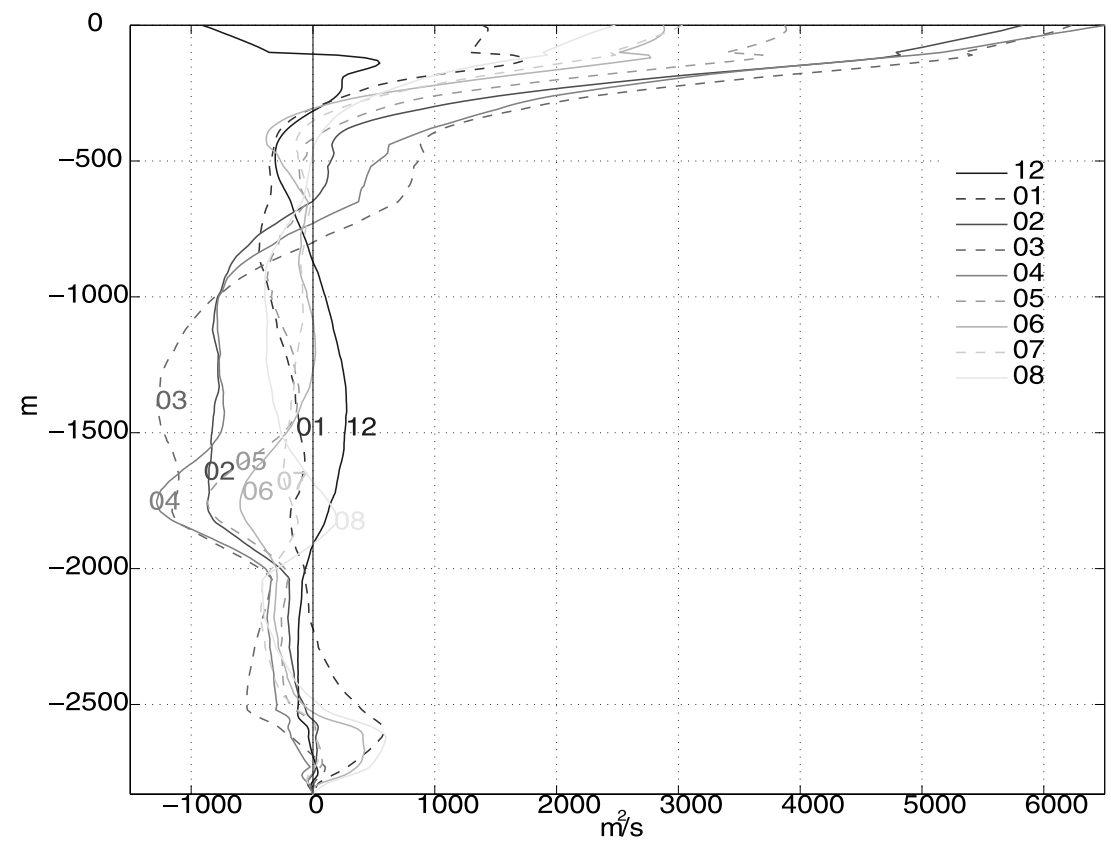

Figure 12. Activation of the NWMS circulation by the deep convection. (a) Daily net flux at the MEDOC boundaries (Sv) in the $0-500 \mathrm{~m}$ layer (thin dark gray line) and in the $500-\mathrm{m}$ bottom layer (thin light gray line). Minimum of the barotropic stream function over the EROM domain (black line). (b) Vertical profile of the monthly net flux at the MEDOC boundaries between December 1986 and August 1987.

improved in order to understand the connection between deep convection and the thermohaline circulation [Testor and Gascard, 2006]. The goal of this section is to evaluate the respective contributions of mesoscale structures and boundary current in the DW spreading out of the NWMS area during and after the convection event. The MEDOC boundary is divided between the East (Balearic Islands, Italy) and the West (Spain, Balearic Islands) subboundaries (see Figure 1). Large-scale (LS) and small-scale (SS) currents are computed using the same technique as in section 4.5. The mesoscale structures and eddies studied in section 4.4 have an upper space scale of approximately 


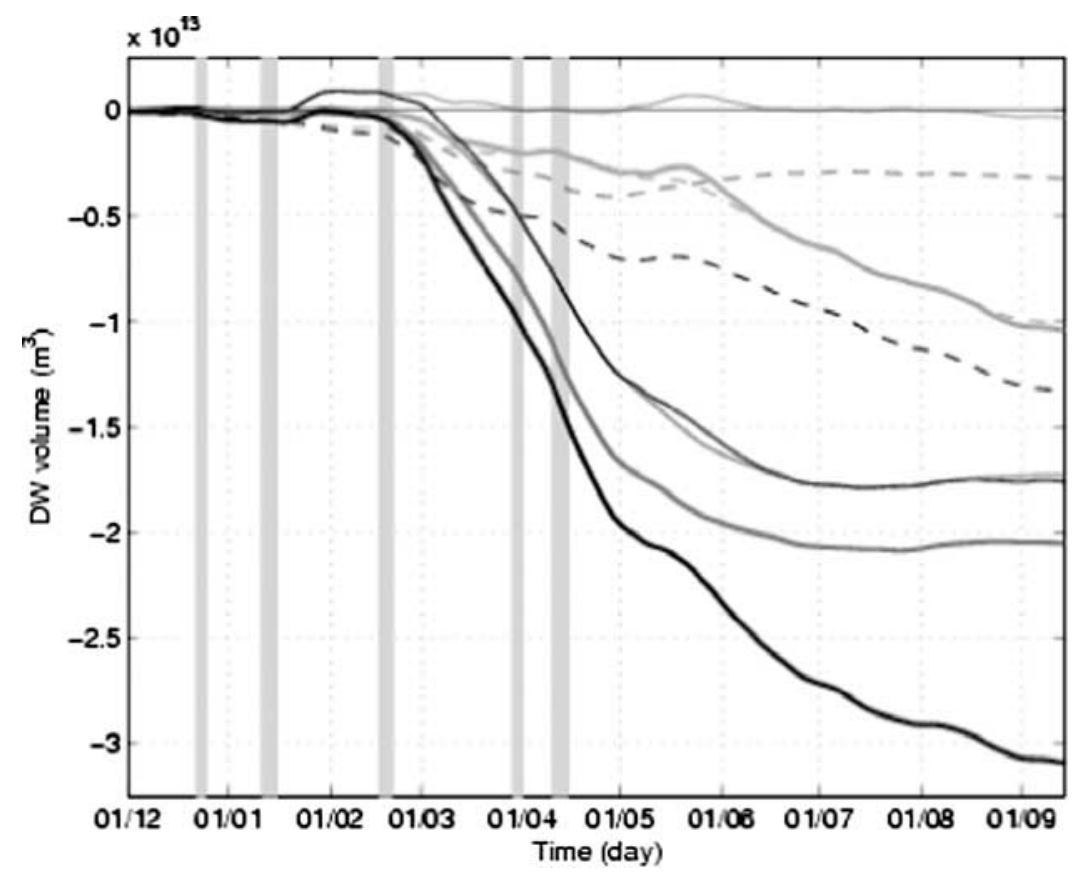

Figure 13. Integrated net DW transport across the MEDOC boundaries since 1 December. Thick full line indicates Total flux. Thin full line indicates large scale flux. Dashed line indicates small-scale flux. Dark gray indicates West boundary. Light gray indicates East boundary. Black indicates whole boundary.

$60 \mathrm{~km}$. We therefore take again this value to differentiate the large-scale and small-scale current, which consequently respectively correspond to the boundary current and the mesoscale structures. To compute the component of water transport due to the boundary current across a given boundary, we then compute the net flux of dense water $\left(\rho>29.10 \mathrm{~kg} \mathrm{~m}^{-3}\right)$ due to the large-scale current: $\iint_{S} \vec{U}_{L S} \cdot \vec{d} s$ where $S$ is the surface formed by the boundary where $\rho>29.10 \mathrm{~kg} \mathrm{~m}^{-3}$ and $\vec{U}_{L S}$ is the large-scale velocity. The same method is used for the mesoscale structures with the small-scale current. The net DW $(\rho>$ $29.10 \mathrm{~kg} \mathrm{~m}^{-3}$ ) fluxes integrated from 1 December across the MEDOC boundary and the East and West boundaries is presented in Figure 13, where we also present the respective contributions of the large-scale current and the smallscale current.

\subsubsection{DW Exported Across the West Boundary}

[62] Between mid-January and the end of April, i.e., during the convection event, DW is mainly exported out of the MEDOC area by the West boundary large-scale flux (Figure 13). The ratio of DW exported across the West and
East boundaries by the large-scale and small-scale currents are given in Table 2. At the end of April, 64\% of the exported DW has been exported across the West boundary by the large-scale current, while mesoscale structures (SS) have exported $21 \%$ of DW across the West boundary. Both processes are actually closely related in this area. The West outgoing large-scale current corresponds to the boundary current that flows southwestward along the Catalan coast. A careful examination of the current and density horizontal fields during this period (not shown here) reveals that the DW present in the convection area is incorporated in the boundary current when mesoscale structures formed in the convection area near the boundary current are dragged by this current. The twice smaller export in EPOM (section 4.7), that reproduces the large-scale current but not the mesoscale structures, confirms that both scales are involved in this process. This is the so-called bleeding effect, first suggested by Madec et al. [1991b] and observed in the area by Send et al. [1996]. In the Catalan sea, both large-scale and small-scale currents are therefore involved in this bleeding effect, which could then be responsible to up to $85 \%$ of the DW export during the convection event (Table 2).

Table 2. Absolute Value and Proportion of DW Exported Across the East and West Boundaries and Contribution of the Boundary Current and Mesoscale Structures Between 1 December 1986 and 30 April 1987, 1 May and 15 September 1987, and 1 December 1986 and 15 September $1987^{\mathrm{a}}$

\begin{tabular}{|c|c|c|c|c|c|c|}
\hline & \multicolumn{2}{|c|}{$1 \mathrm{Dec}$ to $30 \mathrm{Apr}$} & \multicolumn{2}{|c|}{1 May to 15 Sep } & \multicolumn{2}{|c|}{1 Dec to $15 \mathrm{Sep}$} \\
\hline & Absolute $\left(10^{13} \mathrm{~m}^{3}\right)$ & Proportion (\%) & Absolute $\left(10^{13} \mathrm{~m}^{3}\right)$ & Proportion (\%) & Absolute $\left(10^{13} \mathrm{~m}^{3}\right)$ & Proportion $(\%)$ \\
\hline East & 0.29 & 15 & 0.75 & 67 & 1.04 & 34 \\
\hline East LS & 0 & 0 & 0.03 & 3 & 0.03 & 1 \\
\hline East SS & 0.29 & 15 & 0.72 & 64 & 1.01 & 33 \\
\hline West & 1.67 & 85 & 0.38 & 33 & 2.05 & 66 \\
\hline West LS & 1.26 & 64 & 0.47 & 42 & 1.73 & 56 \\
\hline West SS & 0.41 & 21 & -0.09 & -9 & 0.32 & 10 \\
\hline
\end{tabular}

${ }^{a}$ Negative values correspond to net import. LS, boundary current; SS, mesoscale structures. 

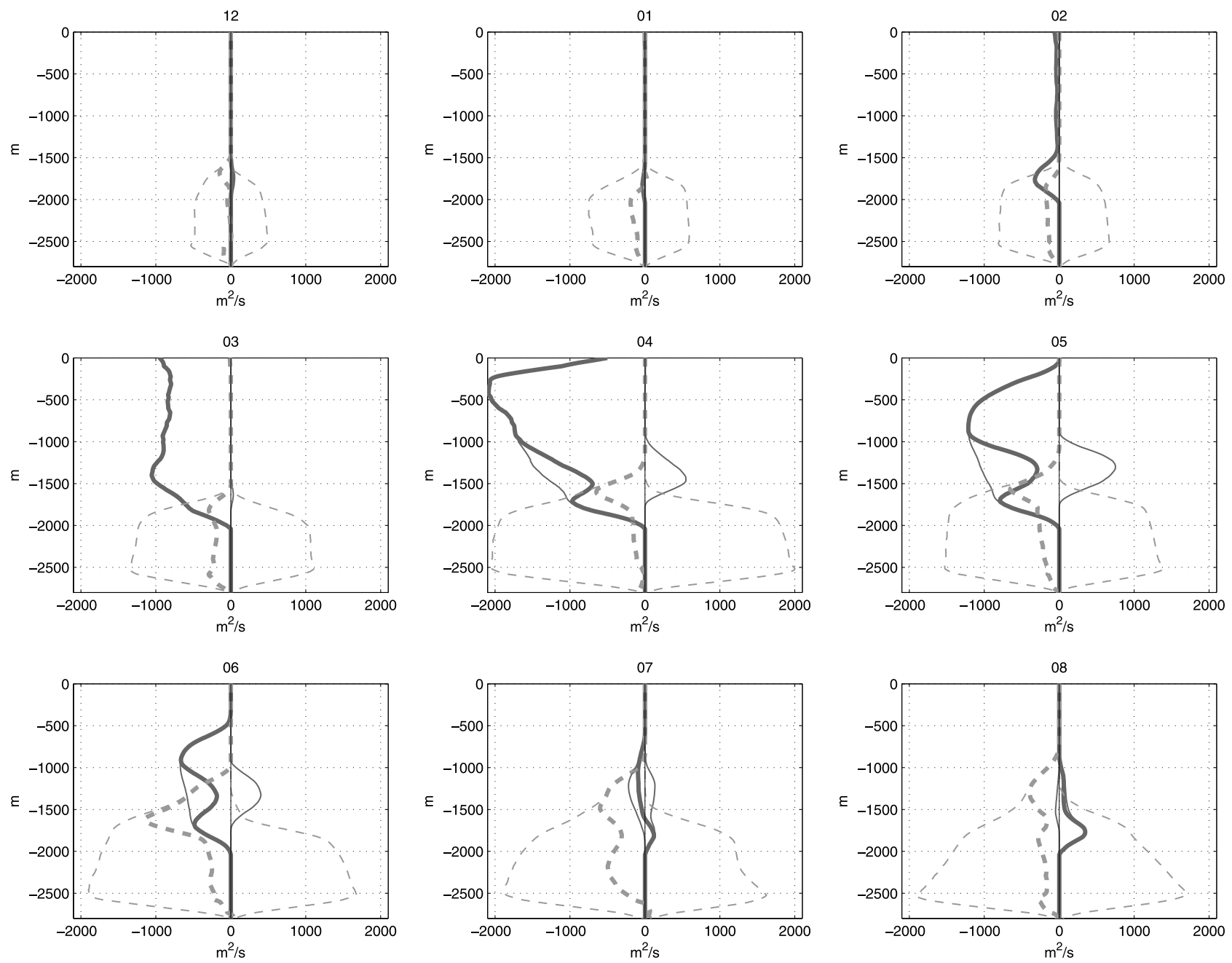

Figure 14. Vertical structure of the incoming, outgoing and net DW fluxes across the MEDOC boundaries since 1 December. Thick full line indicates Net flux. Thin full line indicates large-scale flux. Dashed line indicates small scale flux. Dark gray indicates West boundary. Light gray indicates East boundary. Black indicates whole boundary.

[63] Having evaluated the contribution of the bleeding effect in the DW export, the question of the depth of this export still remains to be answered. The vertical structure of the different fluxes is presented in Figure 14. For clarity, we only show the West large-scale flux and the East small-scale flux, whose contributions in the DW export are predominant, as we will see. In February, DW begins to be exported by the large-scale current across the West boundary between 1500 and $2000 \mathrm{~m}$ depth. The upper depth of this export shallows in March: at this time, DW is present throughout the water column in the convection area and is exported by the largescale current on the whole depth of the West section $(0-$ $1800 \mathrm{~m})$. The upper depth of this export then deepens, as well as the depth of the maximum export, corresponding to the sinking of the DW in the convection area after the convection event. This flux is maximum between 500 and $1000 \mathrm{~m}$ until June (Figure 14). DW being exported by the bleeding effect is therefore not particularly lowered to deeper layers during this process.

[64] After the convection event, the net export across the West boundary decreases and becomes negligible at the end of June (Figures 13 and 14). Moreover, after March, there is also a small net import of DW by the small-scale current (Figure 13 and Table 2) and around $1500 \mathrm{~m}$ depth by the large scale current (Figure 14). This actually corresponds to the import of DW, previously exported across the West boundary into the Catalan sea, by the deep part of the North Balearic current. Finally, the bleeding effect across the West boundary is responsible for up to $33 \%$ of the export of DW that definitively crosses the MEDOC boundary between May and September (Table 2).

\subsubsection{DW Exported Across the East Boundary}

[65] DW export across the East boundary is mainly due to the small-scale current (Figure 13 and Table 2) that corresponds to the mesoscale structures observed in section 4.4 (Figure 13): cyclonic eddies advect dense water out of the convection area. During the convection event itself, the contribution of these eddies exists but it is 6 times smaller than the West boundary bleeding effect contribution $(15 \%$ between 1 December and 30 April, Table 2). At the end of June, the export across the West boundary becomes minor and the DW is mainly exported by the East boundary small- 
scale current (Figure 13). The eddy flux contribution in the DW export is therefore predominant after the convection event. Indeed, between May and mid-September, 64\% of the DW is exported across the East boundary by the small scale current (Table 2).

[66] Contrary to the DW exported across the West boundary, the DW is exported across the East boundary by the small-scale current below $1000 \mathrm{~m}$ depth (Figure 14), with a maximum of net DW export located between 1200 and $1800 \mathrm{~m}$ depth. Even in April, when the flux across the West boundary is maximum around $400 \mathrm{~m}$ depth, no water is exported above $1000 \mathrm{~m}$ by the small-scale flux across the East boundary. When being advected by eddies, DW therefore sinks before to reach the East boundary. Numerical theoretical studies [Hermann and Owens, 1991; Madec et al., 1991b; Jones and Marshall, 1997] showed that mesoscale structures feed on the potential energy available after convection and thus contribute to the deepening of the dense water. This conversion of potential energy into kinetic energy is in agreement with the SSKE increase described in section 4.5 .

[67] The impact of the choice of the space scale (here $60 \mathrm{~km}$ ) on the West boundary small-scale and large-scale fluxes respective contributions is negligible (less than 1\%). However, it does have an impact on the respective contributions of the large-scale and small-scale fluxes across the West boundary: varying the space scale between 48 and $72 \mathrm{~km}$, the contribution of the eddies to the export across the East boundary varies between 75 and 100\%. In all cases, the export of DW across the East boundary is largely due to the eddy fluxes.

[68] During the convection event, the DW formed during the convection event is mainly exported across the West boundary by the bleeding effect throughout the water column. This effect involves the boundary current and, to a smaller extent, the mesoscale structures. The export by the mesoscale structures across the East boundary is predominant after the convection event, and DW exported this way is lowered below $1000 \mathrm{~m}$. Finally, between 1 December 1986 and mid-September, 66\% of the DW is exported across the West boundary and 34\% is exported across the East boundary. These values are comparable with observed values. Using observations made during the 1994-1995 winter, Testor and Gascard [2006] evaluate the eddies originating from the NWMS area to be responsible for $40 \%$ of the DW spreading out of the area, whereas Send et al. [1996] estimated that 50\% of the DW could have been incorporated in the northern boundary current by the bleeding effect. It would be interesting to investigate the impact of interannual variability on these respective contributions.

\subsection{Restratification}

[69] Before the convection event, a layer of light water lays above the pycnocline. In the EROM model, this corresponds to water of density smaller than $29 \mathrm{~kg} \mathrm{~m}^{-3}$. When convection occurs, the water column is vertically mixed and this layer partly disappears. After the deep convection event, restratification occurs and this layer is progressively rebuilt. In this section, as we did in section 4.7 for the DW, we study the restratification process by quantifying the respective roles of mixing, surface forcing and advection (equation (5)) in the light water layer destruction and rebuilding. Three phases are studied in this section: the violent mixing phase (E2-E3), the bottom convection phase (E3-E5) and the restratification phase, after E5.

[70] Figure 15 presents the variations of light water volume in the convection area and the respective contributions of mixing, surface fluxes consumption and advection at the boundary of the convection area between E2 and 15 September 1987. Table 3 gives these values during each phase. Before E2, the volume of light water in the convection area is approximately constant $\left(\sim 0.8 \times 10^{13} \mathrm{~m}^{3}\right)$, the net export and the production by mixing cancel each other. During the violent mixing phase, there is an abrupt volume decrease of $0.75 \times 10^{13} \mathrm{~m}^{3}$ corresponding to the destruction of $94 \%$ of the initial light water layer. This light water is consumed by surface fluxes $(81 \%)$ and mixing $(19 \%)$ (Table 3), and comes from the advection into the convection area $(21 \%)$ and the light water volume decrease $(79 \%)$. Consumption by the surface fluxes and volume decrease are the main terms of equation (5) during the violent mixing phase. Note, however, that mixing and advection are not negligible and that mesoscale structures are responsible for $60 \%$ of this light water advection. This corresponds to the lateral advection of positive buoyancy due to mesoscale structures during the violent mixing phase already shown in section 4.6.

[71] During the bottom convection phase (E3-E5), most of the light water produced comes from the advection $(90 \%$, Table 3 ) and $10 \%$ comes from the surface formation that occurs just before E4. As for the DW (section 5.2.1), most of this net import is due to the large-scale current. This light water is mostly consumed by mixing (71\%) while a smaller part $(29 \%)$ is stored, i.e., participates to the light water layer rebuilding. This mixing corresponds to the stabilization of the dense water characteristics by the mesoscale structures, that mix the dense water formed with this lighter water, as explained in section 4.7. At the end of the convection event, $16 \%$ of the initial layer loss has been rebuilt (Table 3 ).

[72] After the deep convection event, the density of the surface water is strictly smaller than $29 \mathrm{~kg} \cdot \mathrm{m}^{3}$ in the convection area, no surface formation or consumption of light water therefore occurs (Table 3). Between E5 and 20 July 1987 , the light water production is entirely due to the advection, with $56 \%$ due to the eddies and $44 \%$ due to the boundary current (Table 3). A part of the imported water is consumed by mixing but most of it $(69 \%)$ contributes to the light water layer rebuilding. Forty-five percent of the initial light water loss is restored during this period.

[73] After 20 July, the net transport becomes negative and light water is produced by mixing, as before the convection event. Between 20 July and mid-September, 11\% of the light water layer is restored by mixing, corresponding to a renewal rate of $0.17 \mathrm{~Sv}$. On 15 September, $28 \%$ of the initial light water loss is still missing. Assuming that this rate stays constant after the simulation, the light water layer would be completely restored $141 \mathrm{~d}$ after the end of the simulation, i.e., at the beginning of February 1988. The light layer water will not be completely restored before next year deep convection, which will therefore be facilitated. Note, however, that this number is certainly overestimated since our 


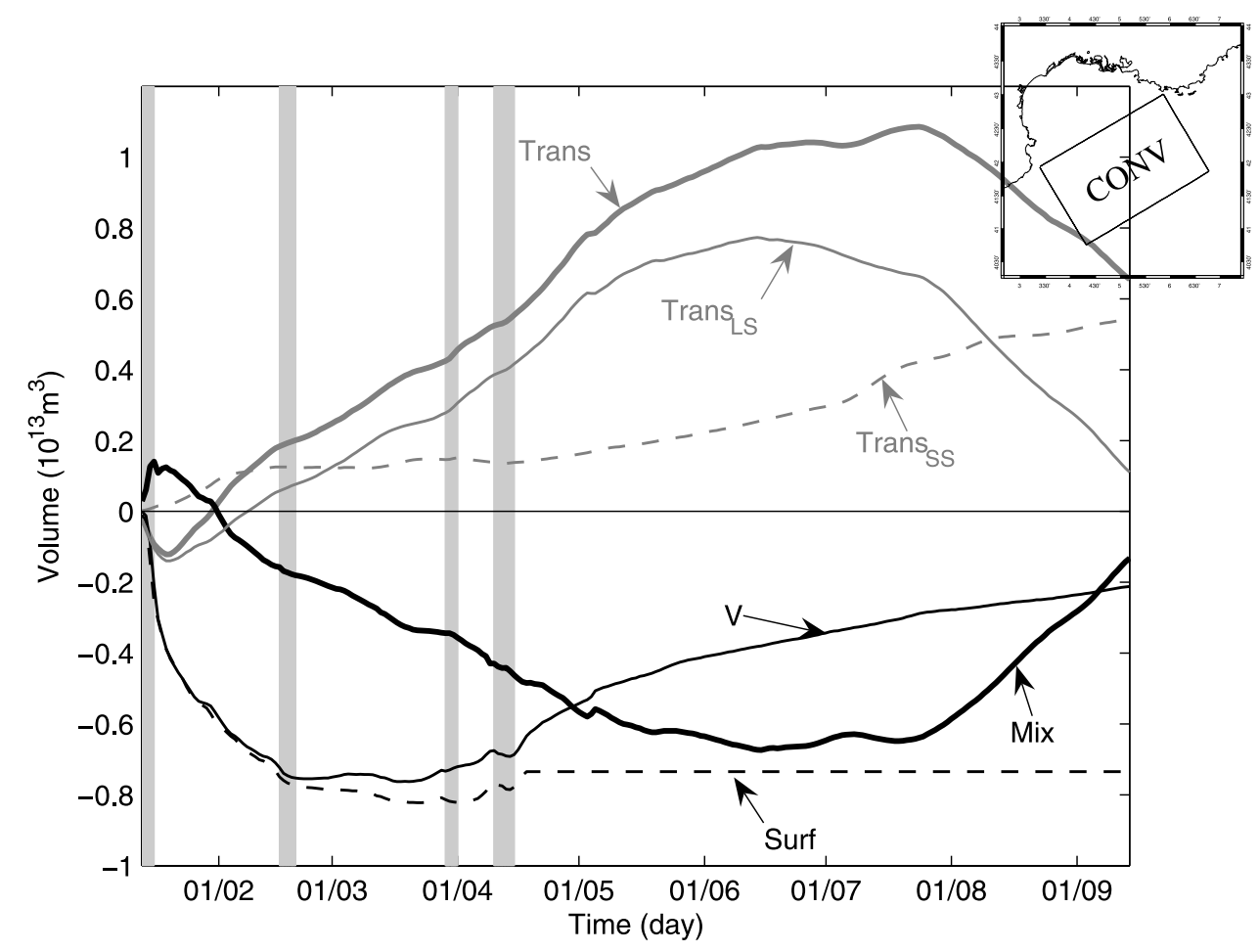

Figure 15. Evolution of the light water $\left(\rho<29 \mathrm{~kg} \mathrm{~m}^{-3}\right)$ between 13 January and 30 April 1987 in the CONV area. Positive/negative values correspond to light water gain/loss by the CONV zone. Grey line indicates integrated net transport across the CONV boundaries since 1 December (thick full line indicates total flux, thin full line indicates large-scale flux, dashed line indicates small-scale flux). Thin black full line indicates total light water volume stored in the CONV area since 13 January. Black dashed line indicates volume of light water formed by the atmospheric fluxes since 13 January. Thick black full line indicates volume of light water produced by mixing since 13 January. Unit of $10^{13} \mathrm{~m}^{3}$.

convection area is larger than the observed area, as mentioned in section 4.3 .

\section{Conclusion}

[74] Winter 1986-1987 was particularly windy and cold. This resulted in a strong bottom convection episode which has been observed and studied by different investigators. We have performed a realistic 1-year simulation for the year 1986-1987 using two different resolution models: a 10-km eddy-permitting model (EPOM) and a 3-km eddy-resolving model (EROM). Both models are forced at the surface by the air-sea fluxes coming from the ERA40 reanalysis [Simmons and Gibson, 2000], and EROM initial and boundary conditions are prescribed by the results of the EPOM simulation. The parameterization of the vertical physics is similar in both models. As far as we know it is the first study that simulates deep convection in the NWMS with high-resolution 3-D models and a realistic atmospheric forcing. This study enables us to evaluate the impact of model resolution on the convection processes numerical representation, to investigate precisely the open ocean convection mechanisms in the NWMS, and to quantify the respective contributions of the mesoscale structures and the boundary current in the DW export.

[75] Both models are able to represent similarly the deep convection global characteristics (convection timing, DW characteristics, maximum MLD). The differences between both simulations is mainly due to the mesoscale processes and mixing representation. The size and evolution of the mesoscale structures are more consistent with previous observations and modeling studies in EROM than in EPOM, as confirmed by the kinetic energy analysis. These structures correspond to baroclinic instabilities which are responsible for the advection of lighter and stratified water into the convection area, facilitating the transfer of buoyancy across the periphery of the convection zone, as shown by the buoyancy analysis. The presence of these structures therefore slows down the mixed layer deepening, reduces

Table 3. $\Delta V$, Mix, Surf, and Trans During the Violent Mixing Phase (E2-E3), the Bottom Convection Phase (E3-E5) and the Restratification Phase (E5-20 July) ${ }^{\text {a }}$

\begin{tabular}{lccc}
\hline & E2-E3 & E3-E5 & E5-20 July \\
\hline$\Delta V$ & -0.75 & 0.12 & 0.34 \\
Mix & -0.18 & -0.30 & -0.16 \\
Surf & -0.77 & 0.04 & 0 \\
Trans & 0.20 & 0.38 & 0.50 \\
Trans $_{\text {LS }}$ & 0.08 & 0.36 & 0.22 \\
Trans $_{\text {SS }}$ & 0.12 & 0.02 & 0.28 \\
\hline
\end{tabular}

${ }^{\mathrm{a}} \Delta V$, light water volume variation; Mix,consumption or formation due to mixing; Surf, surface fluxes; Trans, advection. Units of $10^{13} \mathrm{~m}^{3}$. Advection due to theboundary current ( $\operatorname{Trans}_{\mathrm{LS}}$ ) and mesoscale structures(Trans $\mathrm{SS}$ ) is also indicated. Negative and positive values for Mix, Surf, and Trans correspond to light water consumption and formation, respectively; positive values correspondto light water consumption, respectively, formation. 
the convection volume and helps to the restratification process. The DW volume evolution analysis underlines the difference of DW surface formation, mixing and transport between EROM and EPOM. This difference is mainly explained by the mesoscale structures representation, whose role in the DW spreading and mixing is essential. Finally, because of its better mesoscale structures representation, EROM reproduces more correctly the horizontal extension of the convection area, the restratification process and the DW surface formation, mixing and transport. EPOM can be used for long-term studies of the DW formation, but it should be kept in mind that it overestimates the volume and density of the DW formed.

[76] Using the results of the EROM simulation, we investigate the effects of deep convection on the NWMS circulation. First, the boundary circulation and its mesoscale activity as well as the overturning are enhanced during the deep convection event. Second, two thirds of the DW formed are advected into the Catalan Sea by the bleeding effect, mainly during the convection episode and without being lowered. One third is transported southward and lowered to deep layers by the mesoscale structures after the convection episode. Third, $60 \%$ of the restratification of the water column occurs until end of July and is due to both the boundary current and the mesoscale structures. After July, restratification is due to the mixing and is not complete before next year convection event, which is therefore facilitated.

[77] For both models the convection zone is larger than the observed convection area [Leaman and Schott, 1991; Mertens and Schott, 1998] and extends too much to the southwest. A recent study confirms that this is due to the low resolution of the atmospheric forcing. Applying a dynamical downscaling method to the ERA40 reanalysis, a higher-resolution atmospheric forcing was recently obtained and used to perform an oceanic simulation with EROM, using the same configuration as in the present paper [Hermann and Somot, 2008]. In this simulation, the Northern Current is more intense and in better agreement with the observations than in the present simulation, the large-scale cyclonic gyre is therefore more realistically represented and stronger. Moreover, the size and position of the mixed patch are also in better agreement with the observations. Madec et al. [1996] showed that the intensity of the cyclonic gyre is related to the wind stress curl. In average, during the convection event, the positive part of the wind stress curl is 50\% larger in the simulation presented by Herrmann and Somot [2008] than in the present simulation. In the present simulation, the low resolution of the atmospheric forcing therefore induces the underestimation of the wind stress curl intensity, resulting in a weakening of the large-scale cyclonic gyre, that can less easily trap the dense water mass within its confines, and of the isopycnal doming during the preconditioning phase. Consequently, the mixed patch size is much larger than in the observations, and shifted southwestward. Moreover, because of this overestimation of the mixed patch size, the quantity of dense water formed is also overestimated (the maximum volume of dense water present in the LION area during the convection episode is indeed an order of magnitude smaller in the simulation of Herrmann and Somot [2008]). The strength of the cyclonic gyre was shown to have a strong impact on the baroclinic instabilities, the restratification and the spreading of water masses. Numerical studies performed by Madec et al. [1996], Legg and Marshall [1993] and Legg and Marshall [1998] indeed showed that the stronger the cyclonic gyre is, the more the baroclinic instabilities are suppressed and the more the efficiency of these instabilities in transporting fluid is reduced. Since the cyclonic gyre is too weak in our study, the development of the baroclinic instabilities is much probably overestimated, which, combined with the overestimation of the volume of dense water formed, results in the overestimation of the volume of dense water spread away from the convection area. Moreover, the overestimation of the mixed patch implies the overestimation of the volume of light water destroyed during the convection, therefore of the time required to ensure the complete restratification of the mixed area.

[78] In the future, higher-resolution long-term data set will be available thanks to dynamical downscaling experiments performed with limited area models over Europe and the Mediterranean basin [Sotillo et al., 2005] or data from the ENSEMBLES European project [Hewitt and Griggs, 2004]. This should improve the quality of the air-sea fluxes over the DW formation area, particularly the representation of the extremes, and allow to remove the heat flux correction. However, by now, the ERA40 reanalysis seems to be one of the best forcings available for simulations of years prior to the 1990 s.

[79] The regional scale eddy-resolving model forced by the global scale eddy-permitting model is able to reproduce more correctly mesoscale oceanic processes in NWMS than the global scale model. These mesoscale structures play an important role during the convection episode. This forcing method is therefore legitimate and would be appropriate to study processes that are strongly related to convection, for example NWMS pelagic ecosystems evolution. It would also be instructive to simulate periods of less important convection. Moreover, only monthly variability of the river runoff was taken into account in both simulations. It would be interesting to investigate the effect of the river forcing frequency by taking its daily variability into account, and also to examine the impact of the interannual variability of the river runoff. Finally, it would be instructive to investigate more precisely the impact of the horizontal diffusion and vertical convection parameterizations.

\section{References}

Arakawa, A. (1972), Design of UCLA general circulation model, report, Univ. of Calif., Berkeley.

Artale, V., D. Iudicone, R. Santoleri, V. Rupolo, S. Marullo, and F. D'Ortenzio (2002), Role of surface fluxes in ocean general circulation models using satellite sea surface temperature: Validation of and sensitivity to the forcing frequency of the Mediterranean thermohaline circulation, J. Geophys. Res., 107(C8), 3120, doi:10.1029/2000JC000452.

Auclair, F., S. Casitas, and P. Marsaleix (2000), Application of an inverse method to coastal modelling, J. Atmos. Oceanic Technol., 17, 1368-1391.

Auclair, F., P. Marsaleix, and P. D. Mey (2003), Space-time structure and dynamics of the forecast error in a coastal circulation model of the Gulf of Lions, Dyn. Atmos. Oceans, 36, 309-346.

Auclair, F., C. Estournel, P. Marsaleix, and I. Pairaud (2006), On coastal ocean embedded modeling, Geophys. Res. Lett., 33, L14602, doi:10.1029/ 2006GL026099.

Barnier, B., M. Crépon, and C. Le Provost (1989), Horizontal ocean circulation forced by deep-water formation. part II: A quasi-geostrophic simulation, J. Phys. Oceanogr., 19, 1794-1808. 
Barnier, B., L. Siefridt, and P. Marchesiello (1995), Thermal forcing for a global ocean circulation model using a three year climatology of ECMWF analyses, J. Mar. Syst., 6(4), 363-380.

Béranger, K., L. Mortier, G. Gasparini, L. Gervasio, M. Astraldi, and M. Crépon (2004), The dynamic of the Sicily Strait: A comprehensive study from observations and models, Deep Sea Res., Part II, 51(4-5), $411-440$.

Béranger, K., L. Mortier, and M. Crépon (2005), Seasonal variability of transports through the Gibraltar, Sicily and Corsica Straits from a high resolution Mediterranean model, Prog. Oceanogr., 66(2-4), 341-364, doi:10.1016/j.pocean.2004.07.013.

Bergamasco, A., T. Oguz, and P. Malanotte-Rizzoli (1999), Modeling dense water mass formation and winter circulation in the northern and central Adriatic Sea, J. Mar. Syst., 20, 279-300.

Béthoux, J. (1979), Budgets of the Mediterranean Sea. Their dependence on the local climate and on the characteristics of the Atlantic waters, Oceanol. Acta, 2, 157-163.

Béthoux, J., X. Durrieu de Madron, F. Nyffeler, and D. Tailliez (2002), Deep water in the western Mediterranean: Peculiar 1999 and 2000 characteristics, shelf formation hypothesis, variability since 1970 and geochemical inferences, J. Mar. Syst., 33-34, 117-131.

Blanke, B., and P. Delecluse (1993), Variability of the tropical Atlantic Ocean simulated by a general circulation model with two different mixed layer physics, J. Phys. Oceanogr., 23, 1363-1388.

Blayo, E., and L. Debreu (2005), Revisiting open boundary conditions from the point of view of characteristic variables, Ocean Model., 9, 231-252.

Bozec, A., P. Bouruet-Aubertot, K. Branger, and M. Crpon (2006), Mediterranean oceanic response to the interannual variability of a highresolution atmospheric forcing: A focus on the Aegean Sea, J. Geophys. Res., 111, C11013, doi:10.1029/2005JC003427.

Calmanti, S., V. Artale, and A. Sutera (2006), North Atlantic MOC variability and the Mediterranean outflow: A box-model study, Tellus, Ser. A, $58,416-423$

Castellari, S., N. Pinardi, and K. Leaman (2000), Simulation of the water mass formation processes in the Mediterranean Sea: Influence of the time frequency of the atmospheric forcing, J. Geophys. Res., 105(C10), 24,157-24,181.

Crépon, M., M. Boukthir, B. Barnier, and F. Aikman III (1989), Horizontal ocean circulation forced by deep-water formation. part I: An analytical study, J. Phys. Oceanogr., 19, 1781-1792.

Demirov, E. K., and N. Pinardi (2007), On the relationship between the water mass pathways and eddy variability in the Western Mediterranean Sea, J. Geophys. Res., 112, C02024, doi:10.1029/2005JC003174.

Drillet, Y., R. Bourdall-Badie, L. Siefridt, and C. Le Provost (2005), Meddies in the Mercator North Atlantic and Mediterranean Sea eddy-resolving model, J. Geophys. Res., 110, C03016, doi:10.1029/2003JC002170.

Dufau-Julliand, C., P. Marsaleix, A. Petrenko, and I. Dekeyser (2004), Three-dimensional modeling of the Gulf of Lion's hydrodynamics (northwest Mediterranean) during January 1999 (MOOGLI3 Experiment) and late winter 1999: Western Mediterranean Intermediate Water's (WIW's) formation and its cascading over the shelf break, J. Geophys. Res., 109, C11002, doi:10.1029/2003JC002019.

Echevin, M., M. Crépon, and L. Mortier (2003), Simulation and analysis of the mesoscale circulation in the northwestern Mediterranean Sea, Ann Geophys., 21, 281-297.

Estournel, C., X. Durrieu de Madron, P. Marsaleix, F. Auclair, C. Julliand, and R. Vehil (2003), Observation and modeling of the winter coastal oceanic circulation in the Gulf of Lion under wind conditions influenced by the continental orography (FETCH experiment), J. Geophys. Res. 108(C3), 8059, doi:10.1029/2001JC000825.

Estournel, C., V. Zervakis, P. Marsaleix, A. Papadopoulos, F. Auclair, L. Perivoliotis, and E. Tragou (2005), Dense water formation and cascading in the Gulf of Thermaikos (North Aegean) from observations and modelling, Cont. Shelf Res., 25, 2366-2386.

Gascard, J.-C. (1978), Mediterranean deep water formation, baroclinic eddies and ocean eddies, Oceanol. Acta, 1(3), 315-330.

Gascard, J.-C., and R. A. Clarke (1983), The formation of Labrador Sea water. part II: Mesoscale and smaller-scale processes, J. Phys. Oceanogr., 13, 1779-1797.

Gaspar, P., Y. Gregoris, and J. Lefevre (1990), A simple eddy kinetic energy model for simulations of the oceanic vertical mixing: Tests at station Papa and long-term upper ocean study site, J. Geophys. Res., 95, 16,179-16,193.

Hermann, A. J., and W. B. Owens (1991), Modelling the geostrophic adjustment and spreading of waters formed by deep convection, in Deep Convection and Deep Water Formation in the Oceans, edited by P. C. Chu and J.-C. Gascard, pp. 283-308, Elsevier, New York.

Herrmann, M. J., and S. Somot (2008), Relevance of ERA40 dynamical downscaling for modeling deep convection in the Mediterranean Sea, Geophys. Res. Lett., 35, L04607, doi:10.1029/2007GL032442.
Hewitt, C., and D. J. Griggs (2004), Ensembles-based predictions of climate changes and their impacts, Eos Trans. $A G U, 85(52), 566$.

Jones, H., and J. Marshall (1993), Convection with rotation in a neutral ocean: A study of open-ocean convection, J. Phys. Oceanogr., 23, $1009-1039$

Jones, H., and J. Marshall (1997), Restratification after deep convection, J. Phys. Oceanogr., 27, 2276-2287.

Josey, S. A. (2003), Changes in the heat and freshwater forcing of the eastern Mediterranean and their influence on deep water formation, J. Geophys. Res., 108(C7), 3237, doi:10.1029/2003JC001778.

Katsman, C. A., M. A. Spall, and R. S. Pickart (2004), Boundary current eddies and their role in the restratification in the Labrador Sea, J. Phys. Oceanogr., 34, 1967-1983.

Lascaratos, A., and K. Nittis (1998), A high-resolution three-dimensional numerical study of intermediate water formation in the Levantine Sea, J. Geophys. Res., 103(C9), 18,497-18,512.

Leaman, K. D., and F. Schott (1991), Hydrographic structure of the convection regime in the Gulf of Lions: Winter 1987, J. Phys. Oceanogr., 21, $575-597$.

Legg, S., and J. Marshall (1993), A heton model of the spreading phase of open-ocean deep convection, J. Phys. Oceanogr., 23, 1010-1056.

Legg, S., and J. Marshall (1998), The influence of the ambient flow on the spreading of convected water masses, J. Mar. Res., 56, 107-139.

Lilly, J. M., P. B. Rhines, F. Schott, K. Lavender, J. Lazier, and U. Send (2003), Observations of the Labrador Sea eddy field, Prog. Oceanogr., $59,75-176$

Macdonald, A., J. Candela, and H. Bryden (1994), An estimate of the net heat transport through the Strait of Gibraltar, in Seasonal and Interannual Variability of the Western Mediterranean Sea, Coastal Estuarine Stud., vol. 46, edited by P. L. Violette, pp. 13-32, AGU, Washington, D. C.

Madec, G. (1990), La formation d'eau profonde et son impact sur la circulation régionale en Méditerranée occidentale: Une approche numérique, Ph.D. thesis, Univ. Paris VI, Paris

Madec, G., M. Chartier, and M. Crépon (1991a), The effect of thermohaline forcing variability on deep water formation in the Western Mediterranean Sea: A high resolution three dimensional numerical study, Dyn. Atmos. Oceans, 15, 301-332.

Madec, G., M. Chartier, P. Delecluse, and M. Crépon (1991b), A threedimensional numerical study of deep-water formation in the northwestern Mediterranean Sea, J. Phys. Oceanogr., 21(9), 1349-1371.

Madec, G., F. Lott, P. Delecluse, and M. Crépon (1996), Large-scale preconditioning of deep-water formation in the northwestern Mediterranean Sea, J. Phys. Oceanogr., 26, 1393-1408.

Madec, G., P. Delecluse, M. Imbard, and C. Levy (1998). OPA 8.1, Ocean General Circulation Model, Reference Manual, Note Pôle Modél. 11, Inst. Pierre Simon Laplace, Lab. d'Oceanogr. Dyn. et de Climatol., Paris.

Mantziafou, A., and A. Lascaratos (2004), An eddy resolving numerical study of the general circulation an deep-water formation in the Adriatic Sea, Deep Sea Res., Part I, 51, 921-952.

Mariotti, A., M. Struglia, N. Zeng, and K.-M. Lau (2002), The hydrological cycle in the Mediterranean region and implications for the water budget of the Mediterranean Sea, J. Clim., 15, 1674-1690.

Marsaleix, P., F. Auclair, and C. Estournel (2006), Considerations on open boundary conditions for regional and coastal ocean models, Atmos. Oceanic Technol., 23, 1603-1613, doi:10.1175/JTECH1930.1.

Marshall, J., and F. Schott (1999), Open-ocean convection: Observations, theory, and models, Rev. Geophys., 37(1), 1-64.

MEDAR/MEDATLAS Group (2002), MEDAR/MEDATLAS 2002 database: Cruise inventory, observed and analysed data of temperature and bio-chemical parameters [4 CD-ROMs], IFREMER, Brest, France.

MEDOC Group (1970), Observations of formation of deep-water in the Mediterranean Sea, Nature, 227, 1037-1040.

Mertens, C., and F. Schott (1998), Interannual variability of deep-water formation in the northwestern Mediterranean, J. Phys. Oceanogr., 28, $1410-1424$

Millot, C. (1999), Circulation in the western Mediterranean Sea, J. Mar Syst., 20, 423-442.

Millot, C., and I. Taupier-Letage (2005), Additional evidence of LIW entrainment across the Algerian subbasin by mesoscale eddies and not by a permanent westward flow, Prog. Oceanogr., 66(2-4), 231-250.

Mounier, F., V. Echevin, L. Mortier, and M. Crépon (2005), Analysis of the mesoscale circulation in the occcidental Mediterranean Sea during winter 1999-2000 given by a regional circulation model, Prog. Oceanogr., 66 , $251-269$.

Pairaud, I., and F. Auclair (2005), Combined wavelet and principal component analysis (WEof) of a scale oriented model of coastal ocean gravity waves, Dyn. Atm. Oceans, 40, 254-282.

Petrenko, A., Y. Leredde, and P. Marsaleix (2005), Circulation in a stratified and wind-forced Gulf of Lions, NW Mediterranean Sea: In-situ and modeling data, Cont. Shelf Res., 25, 7-27. 
Sankey, T. (1973), The formation of deep water in the Northwestern Mediterranean, Prog. Oceanogr., 6, 159-179.

Sannino, G., A. Bargagli, and V. Artale (2004), Numerical modeling of the semidiurnal tidal exchange through the Strait of Gibraltar, J. Geophys. Res., 109, C05011, doi:10.1029/2003JC002057.

Schott, F., and K. D. Leaman (1991), Observations with moored acoustic doppler current profilers in the convection regime in the Golfe du Lion, J. Phys. Oceanogr., 21, 558-574.

Send, U., and J. Marshall (1995), Integral effects of deep convection, J. Phys Oceanogr., 25, 855-872.

Send, U., J. Font, and C. Mertens (1996), Recent observations indicates convection's role in deep circulation, Eos Trans. $A G U, 77,61$

Simmons, A., and J. Gibson (2000), The ERA-40 project plan, ERA-40 project report series, Tech. Rep. 1, 63 pp., Eur. Cent. for Medium range Weather Forecast., Reading, U.K.

Somot, S. (2005), Modélisation climatique du bassin méditerranéen: Variabilité et scénarios de changement climatique, Ph.D. thesis, Univ. Toulouse III-Paul Sabatier, Toulouse, France.

Somot, S., F. Sevault, and M. Déqué (2006), Transient climate change scenario simulation of the Mediterranean Sea for the 21 st century using a high resolution ocean circulation model, Clim. Dyn., pp. 1-29, doi:10.1007/s00382-006-0167-z.

Sotillo, M., A. W. Ratsimandresy, J. Carretero, A. Bentamy, F. Valero, and F. Gonzalez-Rouco (2005), A high-resolution 44-year atmospheric hindcast for the Mediterranean basin: Contribution to the regional improvement of global reanalysis, Clim. Dyn., 25(2-3), 219-236, doi:10.1007/ s00382-005-0030-7.

Speer, K., and E. Tziperman (1992), Rates of water mass formation in the North Atlantic Ocean, J. Phys. Oceanogr., 22, 93-104.

Stanev, E., Y. P.-Le Traon, and E. Peneva (2000), Sea level variations and their dependency on meteorological and hydrological forcing: Analysis of altimeter and surface data for the Black Sea, J. Geophys. Res., 105(C7), 17,203-17,216.

Straneo, F. (2004), Heat and freshwater tranport through the central Labrador Sea, J. Phys. Oceanogr., 36, 606-628.

Stratford, K., and K. Haines (2002), Modelling changes in the Mediterranean thermohaline circulation 1987-1995, J. Mar. Syst., 33-34(24), $51-62$.
Testor, P., and J.-C. Gascard (2003), Large-scale spreading of deep waters in the western Mediterranean Sea by submesoscale coherent eddies, J. Phys. Oceanogr., 33, 75-87.

Testor, P., and J.-C. Gascard (2006), Post-convection spreading phase in the northwestern Mediterranean Sea, Deep Sea Res., Part I, 53, 869-893.

THETIS Group (1994), Open-ocean deep convection explored in the Mediterranean, Eos Trans. AGU, 75(19), 217.

Tziperman, E. (1986), On the role of interior mixing and air-sea fluxes in determining the stratification and circulation of the oceans, J. Phys. Oceanogr., 16, 680-693.

Tziperman, E., and K. Speer (1994), A study of water mass transformation in the Mediterranean Sea: Analysis of climatological data and a simple three-box model, Dyn. Atm. Oceans, 21, 53-82.

Ulses, C., C. Grenz, P. Marsaleix, E. Schaaff, C. Estournel, S. Meulé, and C. Pinazo (2005), Circulation in a semi enclosed bay under the influence of strong fresh water input, J. Mar. Syst., 56, 113-132.

Visbeck, M. J., J. Marshall, and H. Jones (1996), Dynamics of isolated convective regions in the ocean, J. Phys. Oceanogr., 26, 1721-1734.

Vörösmarty, C., B. Fekete, and B. Tucker (1996). Global river discharge database, RivDis, UNESCO, Int. Hydrol. Program, Global Hydrol. Archive and Anal. Syst., Paris.

Walin, G. (1982), On the relation between sea-surface heat flow and the thermal circulation in the ocean, Tellus, 34, 187-195.

Wu, P., and K. Haines (1996), Modelling the dispersal of levantine intermediate water and its role in Mediterranean deep water formation, J. Geophys. Res., 101(C3), 6591-6608.

Wu, P., and K. Haines (1998), The general circulation of the Mediterranean Sea from a 100-year simulation, J. Geophys. Res., 103(C1), 1121-1136.

Wu, P., K. Haines, and N. Pinardi (2000), Toward an understanding of deep-water renewal in the eastern Mediterranean, J. Phys. Oceanogr. $30,443-458$

C. Estournel and M. Herrmann, Laboratoire d'Aérologie, Observatoire Midi-Pyrénées, 14 avenue Edouard Belin, F-31400 Toulouse, France. (marine.herrmann@m4x.org)

M. Déqué, F. Sevault, and S. Somot, Centre National de Recherches Météorologiques, Avenue Coriolis 42, F-31057 Toulouse, France. 